\title{
Long-term Economic Modeling for Climate Change Assessment
}

\author{
Y.-H. Henry Chen ${ }^{* \dagger}$, Sergey Paltsev*, John M. Reilly*, Jennifer F. Morris* and \\ Mustafa H. Babiker*
}

\begin{abstract}
A growing concern for using large scale applied general equilibrium models to analyze energy and environmental policies has been whether these models produce reliable projections. Based on the latest MIT Economic Projection and Policy Analysis model we developed, this study aims to tackle this question in several ways, including enriching the representation of consumer preferences to generate changes in consumption pattern consistent to those observed in different stages of economic development, comparing results of historical simulations against actual data, and conducting sensitivity analyses of future projections to key parameters under various policy scenarios. We find: 1) as the economies grow, the empirically observed income elasticities of demand are better represented by our setting than by a pure Stone-Geary approach, 2) historical simulations in general perform better in developed regions than in developing regions, and 3) simulation results are more sensitive to GDP growth than energy and non-energy substitution elasticities and autonomous energy efficiency improvement.
\end{abstract}

Key Words:

Economy-wide Analysis; Model Evaluation; Counterfactual Simulation;

Preference Calibration; Energy Use; Food Consumption

* Joint Program on the Science and Policy of Global Change, Massachusetts Institute of Technology, 77 Massachusetts Ave, E19-411, Cambridge, MA 02139-4307, United States.

${ }^{\dagger}$ Corresponding author (Email: chenyh@mit.edu)

(C) 2015. This manuscript version is made available under the Elsevier user license http://www.elsevier.com/open-access/userlicense/1.0/ 


\section{INTRODUCTION}

The MIT Economic Projection and Policy Analysis (EPPA) model is a computable general equilibrium (CGE) model of the global economy. It has been applied to the study of policy impacts on the economy and emissions, prospects for new technologies, agriculture and land use, and - in some versions - environmental feedbacks on the economy through human health and agricultural productivity. The model can be run in a standalone mode to, for example, investigate the implications of climate and energy policy (e.g. Jacoby and Chen, 2014), or it can be coupled with the MIT Earth System Model (MESM) to form the MIT Integrated Global System Modeling (IGSM) framework (e.g.. Sokolov et al. 2009; Webster et al. 2012). The EPPA model is regularly updated as new global economic data become available. Previous EPPA versions are described in Babiker et al. (2001), Paltsev et al. (2005), and Paltsev et al. (2014a).

EPPA has become a family of models, with different versions developed from the core model to examine in detail specific sectors or technologies such as, for example, private vehicle alternatives (Karplus et al. 2013a, b), the economics of producing jet fuel from biofuels (Winchester et al., 2013), the health and economic effects of air pollution (Nam et al., 2013) or land use change (Gurgel, et al., 2007). ${ }^{1}$ Incorporating such additional features often require substantial data development beyond the basic economic database. Our strategy for this update to EPPA was to first develop a core version of the model (EPPA version 6), with the goal of later adding in details as needed for special studies. In addition to updating the underlying economic database to a benchmark year of 2007, we revisit several key economic features, including the nature of economy-wide productivity growth, capital vintaging, and the relationship of final consumption goods to income growth. The new model provides a platform to develop economic projections to evaluate the implications of energy and climate policies; moreover, it also provides a robust platform for the ongoing model development, during which we plan to incorporate features of earlier versions of EPPA, and build additional features to study more detailed policy questions.

The current version of the model has been designed to allow focus on broader global change topics including land-use change, agriculture, water, energy, air pollution, transportation, population and development. Overall, we seek to understand the linkages of the economy to the broader earth system, the implications of earth system changes for global and regional economic growth, and the implications of economic policies meant to stabilize our relationship with the planet. We start from a theoretically grounded general equilibrium representation of the world economy, and add in the necessary physical detail on resources and environmental implications of their use. General equilibrium models are well-suited to the broader focus because they represent all sectors of the economy and interactions among sectors.

We have two main objectives of the paper. The first objective is to explain new developments in terms of model structure, data, and assumptions. For instance, we incorporate non-homothetic preferences in modeling final consumption to better capture the observed differences in income growth on regional consumption patterns of crops, livestock, and food products. We develop a

\footnotetext{
${ }^{1}$ Publications on model variants and various applications are at: http://globalchange.mit.edu/research/publications.
} 
new vintaging structure for capital investment to better capture the observation that the lifetimes of some capital assets have been extended substantially beyond standard depreciation schedules. We also introduce the potential for exogenous improvements in capital productivity along with labor, land and energy productivity to allow for more balanced patterns of growth and factor prices under varying GDP growth assumptions. We update the main economic data-based on the Global Trade Analysis Project Version 8 (GTAP 8) database - with a benchmark year of 2007 (Narayanan et al., 2012). With the updated data we revise and update the regional businessas-usual (BAU) GDP projections.

The second major objective is to evaluate the reliability of the overall model with these new developments. While large scale applied general equilibrium models of the global economy have been used extensively in many areas, including energy and environmental policy analyses, for decades. A growing concern is whether these models produce reliable projections. We try to tackle that question in several ways. We compare the model's projections against historical data, and test if our revised representation of consumer preferences generates the type of structural changes we have observed in economies as they develop. Then, because we focus on energy, environment and natural resource use and are not experts in macro-economic forecasting, we seek reliability of the macro-economic projections by benchmarking to widely used and respected projections. Finally, we conduct conventional sensitivity analysis of policy results to key parameters. While sensitivity analysis shows model response, it does not tell us much about whether the response is realistic. Policy questions are often asking about new or potential policies and so it is generally not possible to find realistic historical analogues against which to compare model response to a policy shock. And, even if such analogues were to exist, model evaluation would require constructing a counter factual without the policy to test whether the model could reproduce what actually happened with the policy. Still sensitivity analysis can provide useful insight and help us to judge model response.

We note several caveats. First, the model is designed for mid- to long-term projections (over a decade to a century); as currently constructed, the model is not intended to generate or investigate annual or shorter fluctuations due to economic business cycles or shocks to oil or agricultural markets. Second, EPPA is designed as a simulation model to study "what if" questions regarding different underlying economic or policy assumptions. It is not designed to endogenously determine an optimal policy response, or otherwise simulate the behavior of political actors in the face of economic and environmental change. Environmental impacts of economic activities are "external" to private economic decision making, unless specific policies are implemented to price some or all of these externalities. The model incorporates economic distortions (such taxes, subsidies, controlled prices) that are present in the official economic data, but it does not capture unofficial economic transactions that might be substantial in certain parts of the world.

The remainder of the paper is organized as follows: Sections 2 and 3 introduce the theoretical framework and data, respectively; Section 4 presents model evaluation results based on a historical run, and analyzes simulation results for both the reference (BAU) and policy runs, and 
conducts sensitivity analyses with various model parameterizations and settings; and Section 5 provides conclusions and directions for future research.

\section{THEORETICAL FRAMEWORK}

CGE modeling has been widely used in various economy-wide analyses such as trade liberalization effects, interaction between FDI and trade, optimal taxation, modeling for roles of power sector technologies, and energy and environmental policies (Rutherford, et al., 1997; Zhou and Latorre, 2014; Bovenberg and Goulder, 1996; Tapia-Ahumada et al., 2015; van der Mensbrugghe, 2010). The EPPA model is a classical computable general equilibrium model along the lines of these models, with the unique feature that it includes explicit advanced energy conversion technologies and accounting of both greenhouse gas and conventional pollutant emissions. It is a multi-region and multi-sector recursive dynamic model of the world economy solved at 5-year intervals from 2010 through 2100. The current version of the model includes 18 regions and 14 sectors, with labor, capital and multiple energy resources as primary factors. The model represents economic activities of three types of agents in each region: producers, consumers, and the government. Solving the model recursively means that production, consumption, savings and investment are determined by current period prices. Savings supply funds for investment, and investment plus capital remaining from previous periods forms the capital for the next period's production. The model is formulated in a series of mixed complementary problems (MCP), which may include both equations and inequalities (Mathiesen, 1985; Rutherford, 1995; Ferris and Peng, 1997). It is written and solved using the modeling languages of GAMS and MPSGE, and the latter is now a subsystem of the former (Rutherford, 1999).

Versions of the model have been solved as a fully dynamic model, implying forward looking behavior on the part of agents in the economy but to do so required simplification of some of the model features, for example, the explicit vintaging of capital. Babiker et al., (2009) compared similar versions solved either as a forward-looking or a recursive model and found similar results for policy simulations in terms of energy and technology use when the forward looking result that the carbon price rises at the discount rate was imposed on the recursive model. The overall policy costs were lower in the forward-looking model because of the additional flexibility of shifting consumption and investment over time. While forward-looking models are seen as conceptually superior, the implied perfect foresight is a strong assumption as future policies and other outcomes are rarely known with certainty.

\subsection{The Static Model}

In the recursive formulation, the model finds prices, quantities and incomes that represent an equilibrium in each period by solving an optimization problem for three types of agents in each region: the household, producers, and the government. The household owns primary factors including labor, capital, and natural resources, provides them to producers, receives income from the services it provides (wages, capital earnings and resource rents), pays taxes to the 
government and receives net transfers from it. In addition, representative regional household allocates income to consumption and savings.

Producers (production sectors) transform primary factors and intermediate inputs (outputs of other producers) into goods and services, sell them to other domestic or foreign producers, households, or governments, and receive payments in return. To maximize profit, each producer chooses its output level, and - under the given technology and market prices - hires a cost-minimizing input bundle. Production functions for each sector describe technical substitution possibilities and requirements. The government is treated as a passive entity, which collects taxes from household and producers to finance government consumption and transfers.

For a typical CGE model, the activities of different agents and their interactions can be described by three types of conditions: 1) zero-profit conditions; 2) market-clearing conditions; and 3 ) income-balance conditions. Zero-profit conditions represent cost-benefit analyses for economic activities. For the household, the economic activity is consumption that produces utility and for each producer, the activity is production, which results in output. A typical zeroprofit condition expressed in MCP format is:

$$
M C-M B \geq 0 ; Q \geq 0 ;[M C-M B] \cdot Q=0
$$

For instance, if a zero-profit condition is applied on a production activity, then if the equilibrium output $Q>0$, the marginal cost $M C$ must equal the marginal benefit $M B$, and if $M C>M B$ in equilibrium, the producer has no reason to produce. Note that $M C<M B$ is not an equilibrium state since $\mathrm{Q}$ will increase until $M C=M B$. Other activities such as investment, imports, exports, and commodity aggregation are modeled using the Armington assumption (Armington, 1969) and each has its own zero-profit conditions.

For each market-clearing condition, the price level is determined based on market demand and supply. A typical market-clearing condition in MCP format is:

$$
S \geq D ; P \geq 0 ;[S-D] \cdot \mathrm{P}=0
$$

The market-clearing condition states that for each market, if there is a positive equilibrium price $P$, then $P$ must equalize supply $S$ and demand $D$. If $S>D$ in equilibrium, then the commodity price is zero. Similarly, in Condition (2), $S<D$ is not in equilibrium because in this case, $P$ will continue to increase until the market is clear $(S=D)$.

Income-balance conditions specify income levels of household and government that support their spending levels. A typical income-balance condition in MCP format is:

$$
E \geq I ; E \geq 0 ;[E-I] \cdot E=0
$$

The condition that expenditure, $E$ (including household savings) equals income, $I$, always holds in CGE models. Only relative prices matter in general equilibrium models, and thus the empirical formulation requires the choice of a numeraire good. We choose the price of utility for the U.S. as the numeraire, so all other prices are measured relative to it.

We, like many others, use nested Constant Elasticity of Substitution (CES) functions with various inputs to specify preferences and production technologies. CES functions are constant return 
to scale (CRTS), which means if all inputs are doubled, the output will be doubled as well. Although CRTS makes solving the model easier and is compelling for production sectors, when applied to household consumption it implies an income elasticity of one for all goods. This is restrictive and is generally not the case. Enrst Engel, dating back to the 1800's, observed that the expenditure shares on food consumption tend to decrease as income increases, an observation widely referred to as Engel's Law, and confirmed by recent studies (Zhou, 2012; Haque, 2005).

One way to circumvent the income elasticity restriction is to adjust consumption shares between periods as income grows to account for the declining share of food consumption, but CRTS properties will remain within each period so that a policy that reduced income in a period by, for example, 1 percent would lead to 1 percent reduction in food consumption, other things equal. Our strategy is to adopt the approach presented in Markusen (2006) by applying a Stone-Geary preference system within the MPSGE framework. This system requires a shift parameter that changes the reference point of consumption from zero (as in the CES case). The shift parameter, often referred to as the subsistence consumption level, can be calibrated to match estimated income elasticities for each region's household. Note that for a set of constant shift parameters in the StoneGeary system, income elasticities will eventually converge to one as income grows. To overcome this limitation, we recalibrate the shift parameter for each period so the income elasticities match estimated levels, even as income grows. A caveat with this treatment is that, as is the case if consumption shares are recalibrated, the consumer's preference change with each recalibration, and hence measures of equivalent variation are comparable within a period but technically not over recalibrated periods. Addessi (2014) points to the need to distinguish between shifts in and movements along an Engel's curve. The shift parameter adjustment we use with Stone-Geary preferences approximates the income elasticities statistically estimated using a more flexible preference function, and hence represents movement along an Engel's curve, that the less flexible Stone-Geary formulation cannot replicate without the adjustment.

For demonstration purposes, let us consider a utility function $U$ with preference over $N$ commodities indexed by $i$, and use $c_{i}, c_{i}^{*}$, and $w$ to represent consumption of commodity $i$, shift parameter for the consumption of commodity $i$, and the budget, respectively:

$$
u=U\left(c_{1}-c_{1}^{*}, c_{2}-c_{2}^{*}, \ldots, c_{N}-c_{N}^{*}\right)
$$

The income elasticity for the consumption of commodity $i$ is defined as:

$$
\eta_{i}=\left(\frac{c_{i}-c_{i}^{*}}{c_{i}}\right) /\left(\frac{w-\sum_{i=1}^{N} c_{i}^{*}}{w}\right)
$$

Applying the Engel's Aggregation, it can be shown that for a given $\eta_{i}$, the solution for $c_{i}^{*}$ that satisfies Equation (5) is:

$$
c_{i}^{*}=\left(1-\eta_{i}\right) c_{i}
$$

The derivations for Equation (6) and others along with technical details of model structure are provided in the Supplemental Materials. With Equation (6), we can calculate $c_{i}^{*}$ for the base year (i.e., the first period, denoted by $t=0$ ) such that the income elasticity of demand for commodity 
$i$ is $\eta_{i}$. While the same $c_{i}^{*}$ is used for the first two periods $(t=0,1)$, for each later period $c_{i}^{*}$ is recalibrated to approximate $\eta_{i}$. More specifically, from the third period onward $(t \geq 2)$, information from both the adjacent previous period $(t-1)$ and the first period $(t=0)$ is used to update $c_{i}^{*}$ based on Equation (7):

$$
c_{i, t}^{*}=x_{i, t-1}^{T}-y_{i, t-1}^{T} \cdot \frac{x_{i, t-1}^{T}-x_{i, 0}}{y_{i, t-1}^{T}-y_{i, 0}} ; t \geq 2
$$

In Equation (7), $\left(x_{i, 0}, y_{i, 0}\right)$ is the base year consumption bundle, where $y_{i}$ represents the aggregation of all commodities other than $x_{i}$, and $\left(x_{i, t-1}^{T}, y_{i, t-1}^{T}\right)$ is the imputed consumption bundle derived from the given income elasticities and the budget $w_{t-1}$, while using the base year relative price level. With this treatment, we can incorporate the existing income elasticity estimates for the final consumption of crops, livestock, and food sectors. For other EPPA sectors that cannot be directly mapped into sectors in the existing studies, we apply a uniform income elasticity level derived from the Engel's Aggregation. The details of EPPA sectors/commodities will be presented in Section 2.3.

In EPPA intermediate inputs of the food sector are modeled by a Leontief structure. Following Sato (1975) and Guillo' et al. (2011) who point to the need to consider changes in input requirements over time on the production side, we also update the input shares for the food sector based on final consumption trends for crops and livestock. More specifically, we update the food sector input shares such that the percentage changes of crops and livestock inputs are represented by the percentage changes of crops and livestock final consumption levels. Beyond the food sector, we make similar adjustments, for example, with non-price driven efficiency improvement in inputs to production like energy and land (more details are provided in Section $3.3)$.

\subsection{Dynamic Processes}

The dynamics of the model are determined by both exogenous and endogenous factors. Exogenous factors include projections for labor endowment growth, factor-augmented productivity growth, energy productivity growth, and natural resource assets. For each region, we assume that the labor endowment increases proportionally to population growth. We then have the option to specify differential productivity growth for labor, capital and land. Since expectations of future economic growth are often in terms of GDP rather than underlying factors such as labor, land, capital, energy productivity, or resource availabilities, we have included a model feature that automatically calibrates an additional Hick's neutral adjustment on top of any biased growth to match a pre-specified GDP growth rate.

Dynamics determined endogenously include savings, investment, and fossil fuel resource depletion. As in previous versions of EPPA, savings and consumption are aggregated in a Leontief approach in the household's utility function. All savings are used as investment, which meets the demand for capital goods. The capital is divided into a malleable portion $K M_{t}$, with all new investment malleable, and a vintaged non-malleable portion $V_{n, t}$, where $n$ represents a particular vintage category and $t$ represents time period. Capital is region specific, and vintaged 
capital is sector specific. For simplicity in the notation we suppress region and sector subscripts. For a given time period, $n=1$ is 5-year-old vintaged capital in a sector and region, $n=2$ and $n=3$ are the 10- and 15-year-old vintaged capital, respectively, and $n=4$ is capital older than 20 years. The dynamics of the malleable capital are described by:

$$
K M_{t}=I N V_{t-1}+(1-\theta)(1-\delta)^{5} K M_{t-1}
$$

In Equation (8), $\theta$ is the fraction of the malleable capital that becomes non-malleable at the end of period $t-1$, and $I N V_{t-1}$ and $\delta$ are the investment and annual depreciation rate, respectively. The factor of 5 is used because the model is solved in five-year intervals. The newly formed non-malleable capital $V_{1, t}$ is the fraction, $\theta$, of the surviving malleable capital from the previous period:

$$
V_{1, t}=\theta(1-\delta){ }^{5} K M_{t-1}
$$

A limitation of this simple formulation is that vintaged capital has a lifetime of 25 years, 5 as malleable capital, and 20 as vintaged capital. While this is a reasonable assumption for some types of capital, for others (e.g. power plants in the electricity sector) this treatment fails to capture the much longer lifetimes of capital — some of which have been in service for decades. We now allow the possibility for vintaged capital to survive beyond 20 years. We assume that physical productivity of installed vintage capital does not depreciate until it reaches the final vintage. This reflects an assumption that, once in place, a physical plant can continue to produce the same level of output without further investment. This is in conjunction with the assumption that $(1-\theta)$ of capital remains malleable and depreciates continuously. Heuristically, this can be seen as investment in a new physical plant to be part vintaged and part malleable, with the regular updates and replacement (short of the long-term replacement of a plant) accounted in the depreciation of malleable capital. This process can be described by:

$$
V_{2, t+1}=V_{1, t} ; V_{3, t+2}=V_{2, t+1} ; V_{4, t+3}=V_{3, t+2}+(1-\delta)^{5} V_{4, t+2}
$$

In this setting, note that $V_{4, t+3}$ comes not only from $V_{3, t+2}$ but also from $(1-\delta)^{5} V_{4, t+2}$, which is the survived vintage capital beyond 20 years old. The advantage of this formulation is that we effectively extend the life of capital while retaining the formulation that in any given period $t$, there are always only four classes of vintage capital $V_{1, t}, V_{2, t}, V_{3, t}$, and $V_{4, t}$. The effective lifetime of capital is 25 years (the 5-year life of the initial malleable stock, plus the 5-year time step for each of the four explicit vintages) plus the half-life of the final vintage that, with a depreciation rate of 5 percent, is an additional 15 years. In this formulation the economic return to older vintages of capital can fall, possibly to zero implying that it is idle or partly idle. This reflects realities we see in the electric power sector where old inefficient power plants are often idled except during peak demand periods, or if there are requirements or incentives to add renewable capacity when there is little or no demand growth (see Morris et al., 2014 for a discussion and example simulations). Depreciation is thus at least partly endogenous, as in some cases capital that could be used is not because it has become obsolete or its variable costs are higher than that of other competing technologies. 
Figure 1 demonstrates the dynamics for capital stock evolution presented graphically in (8), (9), and (10). To better illustrate the idea, we put "model year" and "vintage year" as the vertical and horizontal axes, respectively, with the former denoting the time period of the model and the latter representing the year when the vintage capital is formed. Therefore, $V_{3,2020}$ for the model year of 2020 was formed in the year 2010. The fact that $V_{4,2025}$ comes from both $V_{3,2020}$ and the survived $V_{4,2020}$ gives an example for the formulation of (10). Vintage capital $V_{n, t}$ is sector specific, and while factor substitution in response to change in relative price is possible for the malleable portion, it is not possible for the non-malleable portion. A further element of the formulation is that the factor shares of $V_{4, t}$ are updated each period to reflect the average of that of $V_{3, t-1}$ and the surviving fraction of $V_{4, t-1}$.

To capture the long-run dynamics of fossil fuel prices, regional fossil fuel resources $R_{e, t}$ are subject to depletion based on regional annual production levels $F_{e, t}$ for fossil resource of type $e$ at period $t$, here suppressing the regional subscript. To align with the five-year time step, values of $F_{e, t}$ are multiplied by a factor of five to approximate depletion in intervening years:

$$
R_{e, t+1}=R_{e, t}-5 F_{e, t}
$$

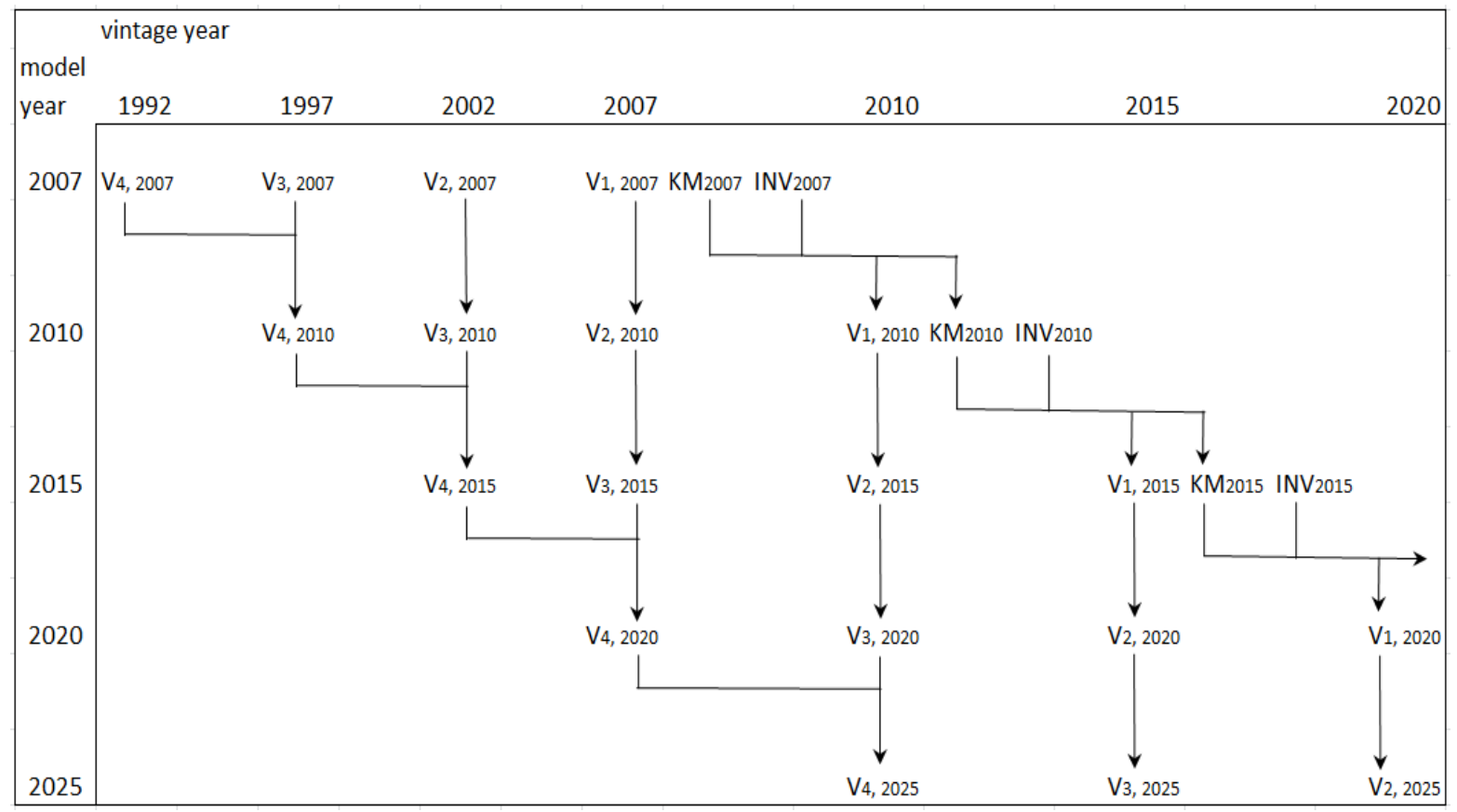

Figure 1. Dynamics for capital stock evolution.

Estimates for oil, gas, and coal resources are from previous versions of EPPA. Details are provided in Paltsev et al. (2005). We incorporate the revised outlook for the growing output of shale gas production due to the technology breakthrough that makes the extraction of shale resources more economically feasible (EIA, 2013; Jacoby et al., 2012; Paltsev et al., 2011). 
Exhaustible resources are depleted over time based on production levels simulated at 5-year intervals in the model, and interpolated include years not explicitly simulated.

\subsection{Regions, Sectors, and Backstop Technologies}

We disaggregate the global economy into 18 regions, as shown in Table 1. While similar to previous version, this additionally breaks out South Korea and Indonesia, to reflect the increasing importance of their economic activities and GHGs emissions in the global economy. Another new feature, shown in Table 2, is Ownership of Dwellings. With this treatment, we are able to better represent the household's energy consumption for heating or cooling. In particular, this makes energy use complementary with expansion of dwellings. While there is the possibility to substitute other inputs for energy within dwellings through investment, for example, in more efficient heating, ventilation, and air-conditioning (HVAC) systems or more efficient building design, general scaling up of the dwelling sector (with increases of population and income) requires proportionally more energy, other things equal.

Based on engineering data (see Section 3 for details), we consider "backstop technologies"new or alternative technology options not presented explicitly in GTAP 8 - as shown in Table 3. This follows an approach in modeling technical change where "blueprints" of potential technologies are specified. In EPPA, these potential technologies are generally higher cost given base year prices of inputs than the conventional technology but as input prices change they may become less costly. Because of this, most backstop technologies have not run at commercial scales or have not operated at all so far, but they may become economic in the future pending changes such as higher fossil fuel prices or policy interventions. The MCP formulation presented in Section 2 allows no output from a backstop technology if it is not economic to operate. Some backstop technologies in Table 3 have been run at nontrivial scales since 2007 (mostly due to incentives or support provided by the government, or limited unique resource availabilities), including wind power, solar power, first generation biofuels, and bio-electricity. We calibrate the model so for historical years (2007 and 2010), the output levels of these technologies match those of the World Energy Outlook from the International Energy Agency (IEA, 2012). 
Table 1. Regions

\begin{tabular}{lll}
\hline Region & EPPA6 & EPPA5 \\
\hline United States & USA & USA \\
\hline Canada & CAN & CAN \\
\hline Mexico & MEX & MEX \\
\hline Japan & JPN & JPN \\
\hline Australia, New Zealand \& Oceania & ANZ & ANZ \\
\hline European Union+ ${ }^{2}$ & EUR & EUR \\
\hline Eastern Europe and Central Asia & ROE & ROE \\
\hline Russia & RUS & RUS \\
\hline East Asia & ASI & ASI \\
\hline South Korea & KOR & ASI \\
\hline Indonesia & IDZ & ASI \\
\hline China & CHN & CHN \\
\hline India & IND & IND \\
\hline Brazil & BRA & BRA \\
\hline Africa & AFR & AFR \\
\hline Middle East & MES & MES \\
\hline Latin America & LAM & LAM \\
\hline Rest of Asia & REA & REA \\
\hline
\end{tabular}

${ }^{2}$ The European Union (EU-27) plus Croatia, Norway, Switzerland, Iceland and Liechtenstein. 
Table 2. Sectors.

\begin{tabular}{lll}
\hline Sector & EPPA6 & EPPA5 \\
\hline Agriculture - Crops & CROP & CROP \\
\hline Agriculture - Livestock & LIVE & LIVE \\
\hline Agriculture - Forestry & FORS & FORS \\
\hline Food Products & FOOD & FOOD \\
Coal & COAL & COAL \\
Crude Oil & OIL & OIL \\
Refined Oil & ROIL & ROIL \\
Gas & GAS & GAS \\
Electricity & ELEC & ELEC \\
Energy-Intensive Industries & EINT & EINT \\
Other Industries & OTHR & OTHR \\
Ownership of Dwellings & DWE & OTHR \\
Services & SERV & SERV \\
Transport & TRAN & TRAN \\
\hline
\end{tabular}

Table 3. Backstop technologies

\begin{tabular}{ll}
\hline Backstop Technology & EPPA6 \\
\hline First generation biofuels & bio-fg \\
\hline Second generation biofuels & bio-oil \\
Oil shale & synf-oil \\
Synthetic gas from coal & synf-gas \\
Hydrogen & h2 \\
Advanced nuclear & adv-nucl \\
IGCC w/ CCS & igcap \\
NGCC & ngcc \\
NGCC w/ CCS & ngcap \\
Wind & wind \\
Bio-electricity & bioelec \\
Wind power combined with bio-electricity & windbio \\
Wind power combined with gas-fired power & windgas \\
Solar generation & solar \\
\hline
\end{tabular}

\subsection{Modeling Penetrations of Backstop Technologies}

Backstop technologies produce goods that are perfect substitutes for current goods. The perfect substitute assumption can mean very rapid scale up of the new technology from no use of it to supply most or all of the market for its good. We employ an adjustment cost approach that captures the combination of extra costs involved if there is demand for a technology to rapidly scale up, as well as resource rents that would accrue to owners of factor inputs unique to the technology and in initially limited supply. This can be patent/licensing of new technology or limits on trained engineers and others who can effectively build the plants. This is accomplished by including a "technology-specific factor" input that is required to operate the backstop technology. The resource rent of the technology-specific factor goes to the representative household, which is the owner of that factor.

The challenge of parameterizing the supply of a technology-specific factor for backstop technologies is that by definition these are technologies that have not yet entered the market. Recent work by Morris et al. (2014) provides a theoretical framework to improve the 
representation of backstop penetration. The formulation creates both rents and adjustment costs in the short term. Adjustment costs are increases in the real cost of the technology that may come about from building plants quickly such that there is waste or unnecessary construction that might be avoided with a more deliberate pace of development. Rents have no direct cost to the economy but may occur when there is a scarce factor-such as knowledgeable engineers to oversee construction or a deliberate attempt to restrict supply through licensing, patents, or other means of exploiting intellectual property rights. They have indirect cost to the economy because they indicate that supply is restricted, but the rents themselves are simply transfers.

Morris et al. (2014) argue that these adjustment costs and rents are a short-term phenomena that should eventually disappear, which they achieve by relating the amount of the technologyspecific factor to the expansion of the sector. The study parameterizes the technology-specific factor supply by the analogue of nuclear power expansion in the U.S. from its introduction in the late 1960's to the mid-80's.

More specifically, Morris et al. argues that during that period when nuclear power was expanding, it was regarded as the next-generation technology poised to take over most of the base load generation; therefore, the experience of nuclear power expansion may provide a good approximation for representing the expansions of other new technologies. To model the penetration of backstop technologies, we incorporate the settings and empirical findings of Morris et al. (2014) into our model:

$$
\begin{aligned}
& \text { bbres }_{b t, t+1}=\alpha \cdot\left[\text { bout }_{b t, t}-(1-\delta)^{5} \cdot \text { bout }_{b t, t-1}\right] \\
& \quad+\beta \cdot\left[\text { bout }_{b t, t}^{2}-(1-\delta)^{5} \cdot \text { bout }_{b t, t-1}^{2}\right]+\text { bbres }_{b t, t} \cdot(1-\delta)^{5}
\end{aligned}
$$

In Equation (12), bbres $_{b t, r, t}$ is the supply of technology-specific factor for technology $b t$ in period $t$, and bout $t_{b t, t}$ is the output of $b t$ in period $t$. The estimates from Morris et al. are $\alpha=$ 0.9625 and $\beta=1.3129 \cdot 10^{-7}$. Morris et al. also specifies a value of 0.3 for the benchmark substitution elasticity between the technology-specific factor and other inputs, demonstrating that this combination of parameters approximately replicates the penetration of nuclear power during its rapid expansion period. Note that this expression includes depreciation of the technologyspecific factor, which assures that should the technology disappear for some period of time, it would require another period of time to rebuild the capacity to expand the technology.

\section{DATA}

\subsection{Economics}

The main economic database used in the model is GTAP 8, with the base year of 2007. GTAP 8 classifies the global economy into 129 regions, 57 sectors (commodities) and 5 types of production factors (GTAP, 2013). For each sector in each region, the database provides information such as bilateral trade and the input-output structure-key inputs for a global CGE model. We aggregates the GTAP 8 data into 18 regions (see Table 1), 14 sectors (see Table 2), 
and 4 factors (labor, capital, land, and natural resources). The mapping details for regions, sectors, and production factors from GTAP 8 are provided in the Supplemental Materials.

The other key data are values of the elasticities of substitution. We draw the elasticities of substitution from previous versions of the model, which were based on literature review (Table 4). Sensitivity analyses using various elasticity values have been conducted extensively using earlier versions of EPPA (Cossa, 2004; Webster et al., 2002). In Section 4, we revisit sensitivities of policy costs to key elasticities.

For a dynamic CGE applied to long-term projections, the inter-temporal calibration of regional BAU GDP growth is crucial. For this work, our first step is to incorporate near-term GDP growth projections in the World Economic Outlook (IMF, 2013) which run through 2018. For later years, the projections of Paltsev et al. (2005) offer starting points, adjusted to reflect long term regional GDP from recent studies, including the World Bank (2013), United Nations (2013), Gordon (2012), and Empresa de Pesquisa Energética (EPE) (2007). For instance, we raise Africa's BAU GDP growth projection beyond 2020 to account for increased population growth projection published by the United Nations. We incorporate the income elasticity estimates for the final consumption levels of CROP, LIVE, and FOOD based on Reimer and Hertel (2004), which used An Implicit Direct Additive Demand System (AIDADS). Since the study of Reimer and Hertel was conducted before the base year of our model, we adjust those elasticities to those given in Table 5, which are functions of income and price levels, to account for changes in economic environment.

Table 4. Substitution elasticities.

\begin{tabular}{lll}
\hline Type of substitution elasticity & Notation & Value \\
\hline Production elasticities & & \\
between energy and non-energy (labor-capital bundle) inputs & e_kl & $0.6-1.0$ \\
between labor and capital & I_k noe_el & 1.0 \\
between electricity and fossil energy bundle for the aggregated energy & 0.5 \\
between fossil energy inputs for the fossil energy bundle & esube & 1.0 \\
between conventional fossil generations & enesta & 1.5 \\
between natural resource and other inputs & esup & $0.3-0.5$ \\
Consumption elasticities & & \\
between non-energy and energy-dwelling bundle & delas & 0.25 \\
between non-energy goods & d_elas & $0.25-0.69$ \\
between energy and dwelling & dw & 0.3 \\
between energy goods & en & 1.5 \\
Trade elasticities & & \\
between domestic and imported goods & sdm & $1.0-3.0$ \\
between imported goods & $\mathrm{smm}$ & $0.5-5.0$ \\
\hline
\end{tabular}

Source: Cossa (2004) 
Table 5. Income elasticity for agricultural and food products.

\begin{tabular}{|c|c|c|c|c|c|c|c|}
\hline & CROP & LIVE & FOOD & & CROP & LIVE & FOOD \\
\hline USA & 0.08 & 0.65 & 0.67 & $\mathrm{CHN}$ & 0.65 & 1.01 & 0.88 \\
\hline CAN & 0.13 & 0.61 & 0.62 & IND & 0.58 & 1.11 & 0.88 \\
\hline MEX & 0.50 & 0.71 & 0.70 & BRA & 0.58 & 0.78 & 0.75 \\
\hline JPN & 0.18 & 0.60 & 0.61 & AFR & 0.63 & 1.05 & 0.89 \\
\hline ANZ & 0.22 & 0.59 & 0.60 & MES & 0.63 & 0.83 & 0.80 \\
\hline EUR & 0.16 & 0.60 & 0.61 & LAM & 0.63 & 0.82 & 0.79 \\
\hline ROE & 0.63 & 0.82 & 0.79 & REA & 0.54 & 1.16 & 0.87 \\
\hline RUS & 0.56 & 0.76 & 0.74 & KOR & 0.30 & 0.61 & 0.61 \\
\hline ASI & 0.64 & 0.86 & 0.81 & IDZ & 0.67 & 1.00 & 0.88 \\
\hline
\end{tabular}

Source: Reimer and Hertel (2004); with adjustments for changes in prices and income levels

\subsection{Backstop Technologies}

For each backstop technology we use a "markup" factor to characterize the economics of that technology in the base year. The markup is defined as the ratio of the backstop technology's production cost to that of the technology that currently produces the same product. For instance, if a backstop technology has a markup value of 1.2 , then in the base year it is $20 \%$ more expensive to operate than the current technology. Markups are derived from the engineering data for backstop technologies. For non-power sector backstop technologies (oil shale, synthetic gas from coal, hydrogen, first generation biofuels, second generation biofuels), the markups are derived from Gitiaux et al. (2012) and the previous version of the model with adjustments for changes in price levels for the 2007 benchmark data from the 2004 level.

Before discussing the markups for power sector backstop technologies, it is worth noting that power plants in duty have often been built decades ago. Taking the power sector in the U.S. for instance, as shown in Figure 2, around three-quarters of the coal-fired capacity has been in operation for at least 30 years (EIA, 2011). In a standard use of data in the I/O and SAM tables it is typically assumed that, absent other information, the base year economy is in equilibrium, which implies that the cost structure in a sector reflects a marginal cost of adding new capacity. Because of increasing environment requirements and other factors it is unlikely that new coal capacity can be added at the cost of fossil generation as reflected in the base year data.

Maintaining the assumption that it could be expanded at this cost would lead to an overexpansion of power generation and favor coal and fossil generation over other advanced technologies where we have used current engineering cost data.

To correct this potential bias in the power sector, we add a new coal generation technology, more expensive than the existing technology, and do not allow expansion of fossil generation at the costs reflected in the SAM. The old capacity remains until it depreciates away. To represent the levelized cost of electricity generation for an existing "average" coal-fired power plant, we use the overnight capital cost data from Bechtel Power Corporation (1981). All costs represented in the base year situation (levelized capital cost, operating and maintenance (O\&M) cost, and fuel costs) are adjusted to the 2007 price levels, and we use a seven-year average of fuel costs based on EIA (2013a) to avoid the short-term fluctuation of energy prices. In Table 6, the 
engineering data for backstop technologies are based on EIA (2010). As the second column of Table 6 shows, in terms of the levelized cost, a new coal-fired unit is around $8 \%$ more expensive to operate compared to the existing unit. Markups for different power sector backstop technologies are also presented in that table. For each technology, the markup and cost structure are used to calibrate the cost function, and through the zero-profit condition presented in Section 2 , the output can also be determined.

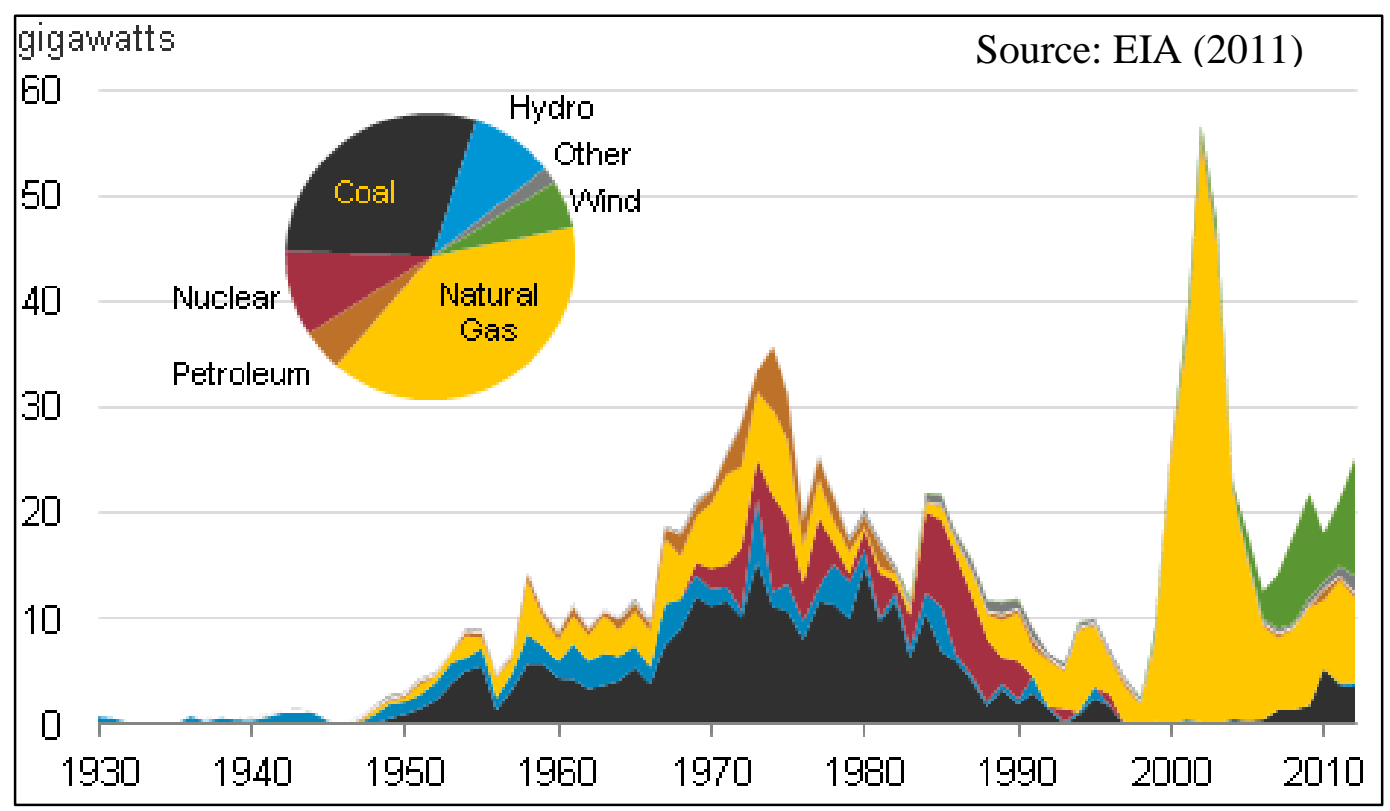

Figure 2. Power sector capacity additions in the U.S. 
Table 6. Markups for power sector backstop technologies.

\begin{tabular}{|c|c|c|c|c|c|c|c|c|c|c|c|c|}
\hline & 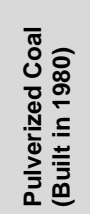 & 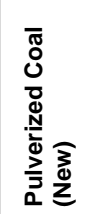 & $\begin{array}{l}\text { U } \\
\text { O্ }\end{array}$ & 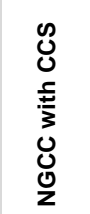 & 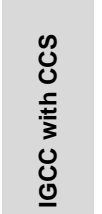 & 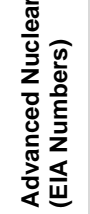 & $\stackrel{\text { Do }}{\xi}$ & 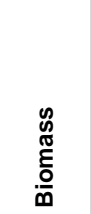 & 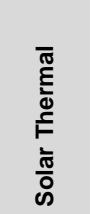 & $\begin{array}{l}\text { à } \\
\frac{1}{0} \\
\text { க) }\end{array}$ & 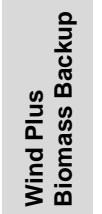 & 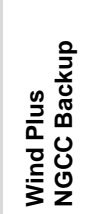 \\
\hline $\begin{array}{l}\text { "Overnight" Capital Cost } \\
\$ / K W\end{array}$ & 1775 & 2196 & 956 & 1909 & 3731 & 3774 & 1942 & 3803 & 5070 & 6097 & 5745 & 2899 \\
\hline $\begin{array}{l}\text { Total Capital Requirement } \\
\$ / K W\end{array}$ & 2059 & 2548 & 1033 & 2138 & 4477 & 5284 & 2098 & 4411 & 5476 & 6584 & 6205 & 3131 \\
\hline $\begin{array}{l}\text { Capital Recovery Charge Rate } \\
\%\end{array}$ & $10.6 \%$ & $10.6 \%$ & $10.6 \%$ & $10.6 \%$ & $10.6 \%$ & $10.6 \%$ & $10.6 \%$ & $10.6 \%$ & $10.6 \%$ & $10.6 \%$ & $10.6 \%$ & $10.6 \%$ \\
\hline $\begin{array}{l}\text { Fixed O\&M } \\
\$ / K W\end{array}$ & 27.81 & 27.81 & 11.82 & 20.11 & 46.58 & 90.93 & 30.61 & 65.03 & 57.30 & 11.79 & 95.64 & 42.42 \\
\hline $\begin{array}{l}\text { Variable O\&M } \\
\$ / K W h\end{array}$ & 0.005 & 0.005 & 0.002 & 0.003 & 0.004 & 0.001 & 0.000 & 0.007 & 0.000 & 0.000 & 0.007 & 0.002 \\
\hline $\begin{array}{l}\text { Project Life } \\
\text { years }\end{array}$ & 20 & 20 & 20 & 20 & 20 & 20 & 20 & 20 & 20 & 20 & 20 & 20 \\
\hline $\begin{array}{l}\text { Capacity Factor } \\
\%\end{array}$ & $85 \%$ & $85 \%$ & $85 \%$ & $80 \%$ & $80 \%$ & $85 \%$ & $35 \%$ & $80 \%$ & $35 \%$ & $26 \%$ & $42 \%$ & $42 \%$ \\
\hline $\begin{array}{l}\text { Capacity Factor Wind } \\
\%\end{array}$ & & & & & & & & & & & $35 \%$ & $35 \%$ \\
\hline $\begin{array}{l}\text { Capacity Factor Biomass/NGCC } \\
\%\end{array}$ & & & & & & & & & & & $7 \%$ & $7 \%$ \\
\hline Operating Hours & 7446 & 7446 & 7446 & 7008 & 7008 & 7446 & 3066 & 7008 & 3066 & 2278 & 3679 & 3679 \\
\hline $\begin{array}{l}\text { Capital Recovery Required } \\
\$ / K W h\end{array}$ & 0.0292 & 0.0362 & 0.0147 & 0.0322 & 0.0675 & 0.0750 & 0.0723 & 0.0665 & 0.1887 & 0.3055 & 0.1782 & 0.0899 \\
\hline $\begin{array}{l}\text { Fixed O\&M Recovery Required } \\
\$ / K W h\end{array}$ & 0.0037 & 0.0037 & 0.0016 & 0.0029 & 0.0066 & 0.0122 & 0.0100 & 0.0093 & 0.0187 & 0.0052 & 0.0260 & 0.0115 \\
\hline $\begin{array}{l}\text { Heat Rate } \\
B T U / K W h\end{array}$ & 8740 & 8740 & 6333 & 7493 & 8307 & 10488 & 0 & 7765 & 0 & 0 & 7765 & 6333 \\
\hline $\begin{array}{l}\text { Fuel Cost } \\
\$ / M M B T U\end{array}$ & 3.15 & 3.15 & 8.18 & 8.18 & 3.15 & 0.50 & 0.00 & 2.61 & 0.00 & 0.00 & 2.61 & 8.18 \\
\hline $\begin{array}{l}\text { Fraction Biomass/NGCC } \\
\%\end{array}$ & & & & & & & & & & & $8.8 \%$ & $8.2 \%$ \\
\hline $\begin{array}{l}\text { Fuel Cost } \\
\$ / K W h\end{array}$ & 0.03 & 0.03 & 0.05 & 0.06 & 0.03 & 0.01 & 0.00 & 0.02 & 0.00 & 0.00 & 0.00 & 0.00 \\
\hline $\begin{array}{l}\text { Levelized Cost of Electricity } \\
\$ / K W h\end{array}$ & 0.07 & 0.07 & 0.07 & 0.10 & 0.11 & 0.09 & 0.08 & 0.10 & 0.21 & 0.31 & 0.21 & 0.11 \\
\hline $\begin{array}{l}\text { Transmission and Distribution } \\
\$ / K W h\end{array}$ & 0.02 & 0.02 & 0.02 & 0.02 & 0.02 & 0.02 & 0.02 & 0.02 & 0.02 & 0.02 & 0.03 & 0.03 \\
\hline $\begin{array}{l}\text { Cost of Electricity } \\
\$ / K W h\end{array}$ & 0.09 & 0.09 & 0.09 & 0.12 & 0.13 & 0.11 & 0.10 & 0.12 & 0.23 & 0.33 & 0.24 & 0.14 \\
\hline Markup / New Pulverized Coal & 0.92 & 1.00 & 0.98 & 1.34 & 1.43 & 1.23 & 1.11 & 1.33 & 2.47 & 3.59 & 2.64 & 1.50 \\
\hline Markup / Coal built in 1980 & 1.00 & 1.08 & 1.06 & 1.44 & 1.55 & 1.33 & 1.20 & 1.44 & 2.67 & 3.89 & 2.85 & 1.62 \\
\hline
\end{tabular}

Sources: EIA (2010) and Bechtel Power Corporation (1981); with adjustments for changes in prices

\subsection{Energy Use and Emissions}

While GTAP 8 has included energy use data from IEA (Narayanan et al., 2012), we incorporate IEA's recent updates by recalibrating the historical energy use in the model based on the World Energy Outlook (IEA, 2012a). We also use IEA's data of combusted $\mathrm{CO}_{2}$ emissions associated with energy consumption (IEA, 2012b). For $\mathrm{CO}_{2}$ emissions related to cement production, which accounts for around $4.5 \%$ of global non-land-use-related $\mathrm{CO}_{2}$ emissions, we draw the data from Boden et al. (2010). At this point, $\mathrm{CO}_{2}$ emissions related to land-use change are exogenously specified based on the RCP8.5 (Riahi et al., 2007). An important near-term direction for expanding EPPA6 is to incorporate land use change and emissions coefficients associated with change such that land use emissions are endogenous as in previous EPPA 
versions, which then reflect land use change as affected by demand for crop, pasture and forest land as simulated in the model (e.g. see Gurgel et al., 2007).

EPPA6 also includes non- $\mathrm{CO}_{2} \mathrm{GHG}$ emissions and urban pollutant emissions. The non- $\mathrm{CO}_{2}$ GHGs included in the model are: methane $\left(\mathrm{CH}_{4}\right)$, perfluorocarbon $(\mathrm{PFC})$, sulfur hexafluoride $\left(\mathrm{SF}_{6}\right)$, and hydrofluorocarbon (HFC); the urban pollutants considered are carbon monoxide (CO), volatile organic compound (VOC), nitric oxide and nitrogen dioxide $\left(\mathrm{NO}_{\mathrm{x}}\right)$, sulfur dioxide $\left(\mathrm{SO}_{2}\right)$, black carbon (BC), organic carbon (OC), and ammonia $\left(\mathrm{NH}_{3}\right)$. Most of the base year non- $\mathrm{CO}_{2}$ GHGs and urban pollutants are drawn from the Emissions Database for Global Atmospheric Research (EDGAR) Version 4.2 (European Commission, 2013). Two exceptions are BC and OC, which are based on Bond (2000).

For later years, energy use levels are determined endogenously by factors such as the patterns of economic growth, technological change (both energy productivity growth and price-driven), and relevant energy or emissions policies. We include a $1 \%$ per year growth in energy productivity for all sectors except for the power sector. We assume a $0.3 \%$ per year of energy productivity growth for power sector as previous EPPA, which leads to an efficiency of conversion from fuels to electricity that approaches 0.5 by the end of the century in the BAU scenario. Energy productivity improvement is not applied to the refinery sector where crude oil is an input converted to refined product. In our setting, once capital is vintaged it is not subject to further energy productivity growth.

\section{MODEL EVALUATION AND SIMULATION}

A challenge for complex models such as ours is evaluation of their performance. While individual parameters of the model can be estimated statistically or informed by econometric studies, the data needed to estimate the entire set of model parameters as a full system rarely exists. And, even where it is possible to estimate parameters of the model from data, often there are multiple candidate structural formulations of the model that may fit historical data well, yet the implications for projections can be quite different. For example, Webster et al. (2008a) show that because of collinearity in GDP growth and time, a model that includes either a strong autonomous trend in energy efficiency improvement (due implicitly to ongoing technical change) or one that formulates an income elasticity of demand for energy can explain equally well the historical data for 1975 to 2000 for the US, yet these different approaches can lead to very different projections of energy use and GHG emissions for different future growth rates of GDP. In a similar vein, Lanz et al. (2014) can predict well historical land use change and population with quite different parameter values that generate similar business-as-usual forecasts but behave differently in response to an exogenous forcing.

We take several approaches to evaluate the performance. In Section 4.1, we simulate the model for an historical period and compare energy and agriculture projections to actual data to evaluate performance. In Section 4.2 and 4.3 we compare forecasts in a BAU scenario the current and previous versions of the model for overall economic growth and agricultural output. Of course, that does not tell us which representation is better, or if the results are not different, 
that either version is particularly reliable, but it does provide some insight into whether the changes between the versions greatly affect the results. In the case of agriculture, we believe the performance of the current version, given closer approximation of flexibly estimated demand parameters, should be an improvement over the previous version, and so the question is how different are new projections. We then simulate the model under a GHG policy constraint in Section 4.4, and then finally in Section 4.5 conduct sensitivity analysis on key parameter that affect policy costs and outcomes to gauge some sense of the range of outcomes.

\subsection{Historical simulation}

An interesting exercise for dynamic CGE modeling is to run the model starting from an earlier time point, and see to what extent the simulation results match historical numbers. To do this, we recalibrate the model for the base year of 2000. The model was not developed with the intention that it would endogenously produce a baseline GDP growth, but rather given a GDP scenario we would like it to reliably project energy and agriculture production. Hence, we benchmark the historical GDP growth for each region to IMF (2015) data through to 2010. This allows us to simulate ten historical years and compare the projections beyond the base year to actual data for energy production from IEA (2014), and for agriculture production and consumption from the GTAP data. Since we simulate the model in five-year time steps, the simulation will include three time periods: 2000, 2005, and 2010. The regional GDP growth figures are shown in Table 7.

Table 7. Historical average GDP growth rates by region.

\begin{tabular}{rccccc}
\hline & $2000-2005$ & $2005-2010$ & & $2000-2005$ & $2005-2010$ \\
\hline USA & $2.53 \%$ & $0.76 \%$ & CHN & $9.10 \%$ & $10.54 \%$ \\
CAN & $2.54 \%$ & $1.27 \%$ & IND & $6.77 \%$ & $8.31 \%$ \\
MEX & $1.64 \%$ & $1.93 \%$ & BRA & $2.86 \%$ & $4.44 \%$ \\
JPN & $1.20 \%$ & $0.33 \%$ & AFR & $5.47 \%$ & $5.79 \%$ \\
ANZ & $3.42 \%$ & $2.54 \%$ & MES & $4.65 \%$ & $4.95 \%$ \\
EUR & $1.82 \%$ & $0.92 \%$ & LAM & $2.93 \%$ & $4.92 \%$ \\
ROE & $5.77 \%$ & $3.76 \%$ & REA & $5.47 \%$ & $5.16 \%$ \\
RUS & $6.12 \%$ & $3.55 \%$ & KOR & $4.73 \%$ & $4.11 \%$ \\
ASI & $4.49 \%$ & $4.62 \%$ & IDZ & $4.73 \%$ & $6.07 \%$ \\
\hline
\end{tabular}

Source: IMF (2015)

Table 8 compares the simulated results with the data. For exposition purposes, the 18 regions are aggregated into three: developed, other G20, and the rest of world. The table note defines these regions. Detailed regional results are provided in the Supplemental Materials. We find that, in general, projections for developed region perform relatively well (within $+10.0 \%$ and $-3.6 \%$ depending on the fuel. Simulated and actual fuel use for other G20 and rest of world tend to diverge more. For instance, the projection for coal consumption of other G20 region in 2010 is $30.7 \%$ lower than the actual number.

The main reason for this deviation comes from the fact that China's actual coal consumption in $2010(67.99 \mathrm{EJ})$ is around 60\% higher than the projected value (42.34 EJ). The very rapid 
growth of coal use in China over that decade was generally a surprise to everyone, and appears to be an anomaly because all future projections suggest coal use growing slower and ultimately peaking. This period may reflect a heavy government focused effort on energy-intensive infrastructure, not well captured in the general parameterization for China. Here, we run the historical simulation without considering any policies during that period, thus, for those regions where policies may have had a significant impact on energy use the model simulation results would be expected to be at odds with the historical data that included the policy influence. Finally, as the discussion with respect to the Webster et al. (2008) results suggest there is an indeterminacy in whether reductions in energy use per unit of GDP that are widely observed are a function of income per capita, or simple time trends of efficiency improvement. In parameterizing the energy efficiency trends, we observed that the rate of improvement in the Energy/GDP ratio was greater in more developed countries and much less or even no improvement in poorer regions. This differential rate of improvement leads us to parameterize more efficiency improvement in wealthier regions and less in poorer regions, but improving over the forecast period as we generally project higher per capita income in the future. While there is not a formal functional relationship between income per capita and energy use, it is implicit in the parameterization of the model and the development of the BAU. Thus, going back to year 2000, when countries GDP per capita was lower, would, if we followed this strategy completely, lead us to slow the efficiency improvement for that decade. Of course, these results suggests that a structural formulation that included an income elasticity for energy that varied by per capita income might provide a better hindcast, and especially for cases with varying GDP growth rates, a better forecast.

Table 8. Historical simulation for fossil energy consumption.

\begin{tabular}{|c|c|c|c|c|c|c|}
\hline Unit: EJ & 2000 & & 2005 & & 2010 & \\
\hline Coal & history & model & history & model & history & model \\
\hline Developed & 44.49 & 44.49 & 44.71 & 44.62 & 40.35 & 44.38 \\
\hline Other G20 & 44.31 & 44.31 & 65.70 & 51.81 & 93.24 & 64.60 \\
\hline Rest of World & 9.80 & 9.80 & 10.67 & 10.51 & 11.86 & 11.74 \\
\hline Global & 98.60 & 98.60 & 121.08 & 106.95 & 145.45 & 120.73 \\
\hline \multicolumn{7}{|l|}{ Oil } \\
\hline Developed & 78.96 & 78.96 & 82.42 & 82.83 & 77.05 & 82.91 \\
\hline Other G20 & 40.84 & 40.84 & 49.56 & 47.82 & 59.61 & 56.87 \\
\hline Rest of World & 31.09 & 31.09 & 35.49 & 34.54 & 35.57 & 39.33 \\
\hline Global & 150.89 & 150.89 & 167.47 & 165.19 & 172.22 & 179.11 \\
\hline \multicolumn{7}{|l|}{ Gas } \\
\hline Developed & 46.94 & 46.94 & 47.25 & 48.30 & 50.52 & 48.71 \\
\hline Other G20 & 20.74 & 20.74 & 25.20 & 24.57 & 32.09 & 27.76 \\
\hline Rest of World & 19.62 & 19.62 & 26.11 & 21.61 & 32.11 & 24.85 \\
\hline Global & 87.29 & 87.29 & 98.56 & 94.48 & 114.71 & 101.32 \\
\hline
\end{tabular}


The comparison between the simulated final consumptions of food and agricultural products and their historical counterparts is presented in Table 9. Since the GTAP database does not cover the year 2000, we impute data for that year based on Narayanan et al. (2012) and the World Bank (2015b), and the 2004 and 2007 data are from the dual databases of GTAP 8. It is worth noting that unlike energy consumption data that are recorded in a physical unit, the GTAP data of different years are measured in current U.S. dollars of respective years. For countries other than the U.S., to eliminate changes in consumption levels (measured in dollars) due to changes in nominal exchange rates, we adjust the GTAP data of various years based on the World Bank's exchange rates database (World Bank, 2015a). Thus, the historical data in terms of 2000 U.S. dollars are net of changes in nominal exchange rates over time. A caveat for longitudinal comparison between different GTAP databases is that: even with the exchange rates adjustment, the comparison is still subject to potential bias caused by database rebalancing for each period (GTAP, 2013).

For simplicity, Table 9 considers those regions with a single currency presented in each region. Since the historical simulation is also run at a five-year time step starting from 2000, to facilitate the comparison between historical and simulated numbers, we present simulated results for 2004 and 2007 based on the model outputs for 2000 and 2005, and 2005 and 2010, respectively, interpolating a constant annual growth rate between each forecast year. The comparison between historical and simulated numbers reveals, probably not surprisingly, that projection error increases with time. In general, simulated results for developed regions tend to be closer to their historical counterparts, with the exception for the final consumption of livestock products, where the 2007 GTAP's data for developed regions are much lower than the 2004 numbers. For instance, in 2004, the average deviations of the model projections from the GTAP numbers for crop, livestock, and food consumption are $-4.0 \%, 0.7 \%$, and $-0.3 \%$ for developed regions, while for developing regions the average deviations are $-6.2 \%, 1.8 \%$, and $-1.7 \%$. However, in 2007, for developed regions the deviations become $-1.9 \%, 57.8 \%$, $-1.8 \%$, and for developing regions they are $-18.7 \%,-8.3 \%,-14.5 \%$.

The most important lesson learned here was the difficulty of getting a consistent time series comparable to the projection of the model. GTAP recalibration to balance global data and the need to make exchange rate correction and interpolate between forecast years to match years for which we have historical data means we are not directly comparing a model forecast to actual data. For example, economic growth was not even across the five-year model intervals, and so it is unfortunate that the comparison year is 2007, where error from assuming a constant growth rate between periods may be greatest. 
Table 9. Historical simulation for the final consumption of food and agricultural products

\begin{tabular}{|c|c|c|c|c|c|c|c|c|c|c|c|c|}
\hline \multicolumn{13}{|l|}{ History } \\
\hline & & BRA & CAN & CHN & EUR & IDZ & IND & JPN & KOR & MEX & RUS & USA \\
\hline \multirow[t]{3}{*}{2000} & crop & 8.20 & 3.23 & 30.03 & 61.83 & 7.29 & 31.46 & 22.29 & 8.72 & 8.30 & 8.23 & 32.64 \\
\hline & live & 3.77 & 1.19 & 35.14 & 16.80 & 5.20 & 26.67 & 6.83 & 1.89 & 5.00 & 8.56 & 13.98 \\
\hline & food & 56.22 & 28.35 & 82.50 & 492.77 & 22.79 & 53.79 & 228.06 & 27.53 & 77.06 & 30.25 & 342.32 \\
\hline \multirow[t]{3}{*}{2004} & crop & 9.15 & 3.54 & 42.97 & 66.66 & 8.69 & 39.94 & 23.35 & 10.57 & 8.74 & 10.41 & 35.79 \\
\hline & live & 4.21 & 1.31 & 50.28 & 18.11 & 6.20 & 33.86 & 7.16 & 2.29 & 5.26 & 10.83 & 15.33 \\
\hline & food & 62.77 & 31.15 & 118.07 & 531.27 & 27.16 & 68.29 & 238.92 & 33.38 & 81.13 & 38.27 & 375.40 \\
\hline \multirow[t]{3}{*}{2007} & crop & 11.78 & 3.05 & 59.50 & 64.89 & 13.29 & 56.30 & 21.30 & 10.49 & 9.11 & 18.22 & 41.96 \\
\hline & live & 5.40 & 0.83 & 69.05 & 14.58 & 9.51 & 46.93 & 4.87 & 2.15 & 5.57 & 20.12 & 7.94 \\
\hline & food & 80.34 & 34.66 & 163.73 & 571.98 & 42.34 & 93.53 & 223.57 & 41.12 & 97.98 & 67.88 & 412.91 \\
\hline \multicolumn{13}{|l|}{ Model } \\
\hline & & BRA & CAN & $\mathrm{CHN}$ & EUR & IDZ & IND & JPN & KOR & MEX & RUS & USA \\
\hline \multirow[t]{3}{*}{2000} & crop & 8.20 & 3.23 & 30.03 & 61.83 & 7.29 & 31.46 & 22.29 & 8.72 & 8.30 & 8.23 & 32.64 \\
\hline & live & 3.77 & 1.19 & 35.14 & 16.80 & 5.20 & 26.67 & 6.83 & 1.89 & 5.00 & 8.56 & 13.98 \\
\hline & food & 56.22 & 28.35 & 82.50 & 492.77 & 22.79 & 53.79 & 228.06 & 27.53 & 77.06 & 30.25 & 342.32 \\
\hline \multirow[t]{3}{*}{2004} & crop & 8.90 & 3.29 & 39.89 & 63.38 & 8.34 & 37.37 & 22.70 & 9.26 & 8.83 & 9.79 & 34.7 \\
\hline & live & 4.20 & 1.30 & 51.16 & 18.26 & 6.35 & 35.09 & 7.23 & 2.12 & 5.39 & 10.66 & 15.41 \\
\hline & food & 62.16 & 30.74 & 115.99 & 530.27 & 27.20 & 66.98 & 238.73 & 30.87 & 81.39 & 37.28 & 373.72 \\
\hline \multirow[t]{3}{*}{2007} & crop & & 3.40 & 50.76 & 65.08 & & 44.38 & 22.63 & 9.76 & 9.94 & 11.05 & 37.6 \\
\hline & live & 4.70 & 1.37 & 68.75 & 19.25 & 7.46 & 44.05 & 7.40 & 2.30 & 6.17 & 12.12 & 16.51 \\
\hline & food & 69.06 & 32.17 & 152.07 & 553.47 & 31.61 & 81.19 & 242.00 & 33.39 & 92.09 & 42.22 & 392.74 \\
\hline
\end{tabular}

Sources: Historical data of 2004 and 2007 are from Narayanan et al. (2012); the 2000 data are imputed based on Narayanan et al. and the World Bank (2015b). Simulation results for 2004 and 2007 are imputed based on the model outputs of 2000 and 2005, and 2005 and 2010, respectively, assuming a constant annual growth rate for each variable.

\subsection{Benchmarking of Economic Growth}

While GDP is endogenously determined as a function of investment, savings, productivity, and resource constraints, we do not see the model as a tool to project the fundamentals of economic growth. Instead we survey other GDP forecasts and use the Hick's neutral productivity factor as an instrument to match a BAU scenario of GDP growth. Once we have the BAU scenario then endogenous nature of GDP determination allows us to investigate how policies that constrain options, or resource limits or environmental feedbacks might affect that BAU growth. For GDP growth from the base year to present and into the near-term, we benchmark growth to regional GDP growth projections in the IMF's World Economic Outlook. The most recent data and projections are generally higher than the EPPA5 numbers before 2020, and therefore, the global GDP growth projections for the next decade are somewhat faster than previous projections, as shown in Figure 3a. For years around the middle of the century, projections for the global GDP growth rates are lower than those of EPPA5 due to slower GDP growth projections for developed regions, including USA and EUR, and for the last half of the $21^{\text {st }}$ century, the global GDP growth rates eventually approximate EPPA5's levels because of the higher growth in AFR. Under the new projection, the global GDP level for 2020 is $3.8 \%$ higher than that of EPPA5, and the levels for 2050 and 2100 are $1.2 \%$ and $5.9 \%$ lower than those of 
EPPA5, respectively, as shown in Figure 3b. These small differences in the overall level of GDP, especially in the distant future, mean that the decades-long global growth rates are little changed, but with more differences for individual regions (See Section 3.1 and Supplemental Materials for details).

Note that the BAU GDP growth is calibrated in a scenario where expansion of coal-fired power generation is restricted in the USA and EUR and as a result, coal-fired power outputs will not exceed their 2010 levels, which was not the case in previous versions of the model. The treatment for coal-fired power is now in line with the BAU projections of IEA (2012) and EIA (2013b), and we believe it better represents the reality of new environmental regulations in these regions.

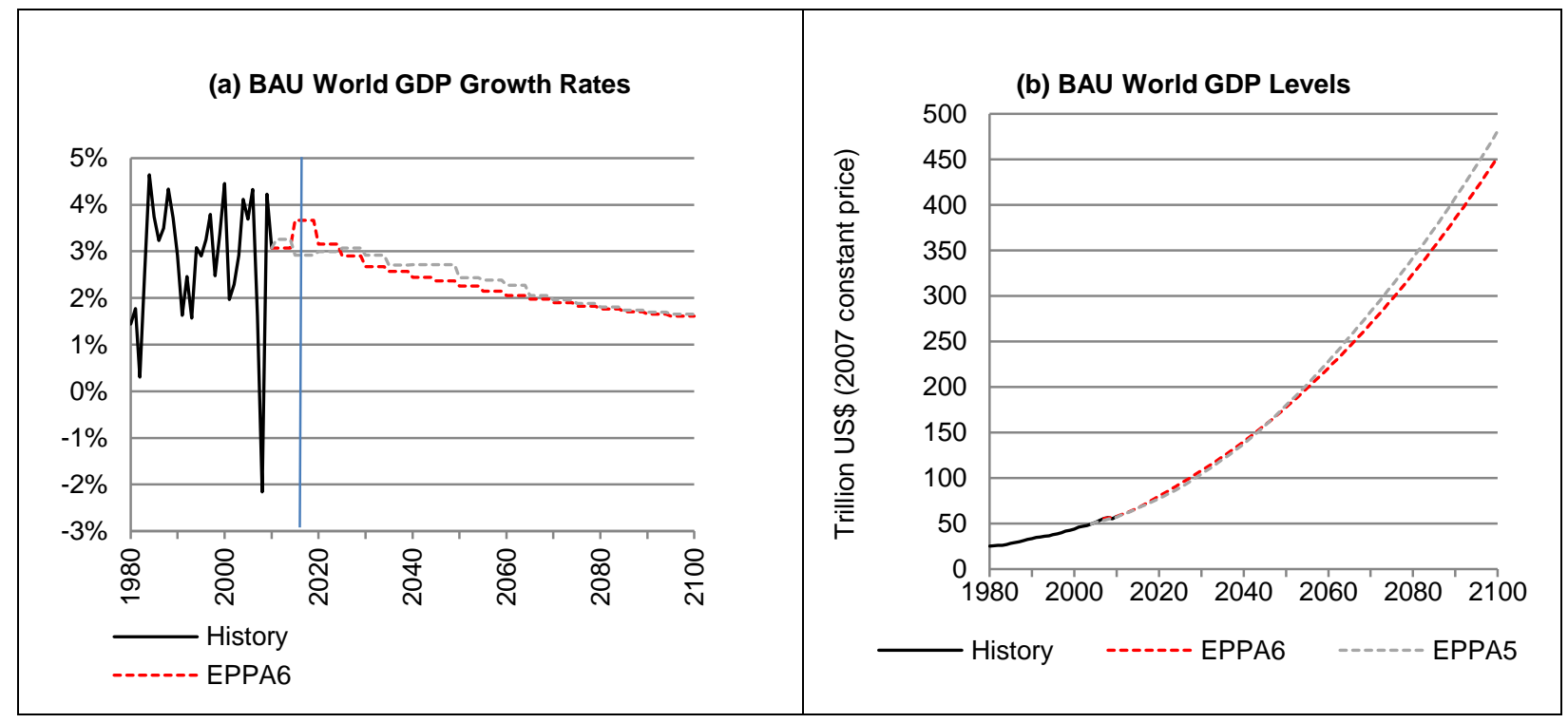

Figure 3. BAU world GDP growth projection.

\subsection{Final Consumption for Food and Agricultural Products}

In the case of food consumption and agricultural production, we believe the current structure is a significant improvement over the previous formulation because we can better approximate econometric estimates of incomes elasiticities for these goods. Consumption of food the implications for agricultural production is important for us, as the need to expand agricultural production may induce land-use changes and result in GHG implications. In the base version of our new formulation we incorporate the income elasticity estimates for the final consumption of CROP, LIVE, and FOOD from Reimer and Hertel (2004) as previously discussed and shown in Table 5, with the estimates adjusted to reflect the economic environment of our base year. We contrast these results a simulation with a pure CES result where the income elasticity is 1.0, and with a separate set of income elasticity estimates produced by the USDA (2013) based on the International Comparison Program (ICP) data across 144 countries (see Table 10). 
Table 10. Income elasticity for agricultural and food products from USDA.

\begin{tabular}{|c|c|c|c|c|c|c|c|}
\hline & CROP & LIVE & FOOD & & CROP & LIVE & FOOD \\
\hline USA & 0.210 & 0.260 & 0.346 & $\mathrm{CHN}$ & 0.617 & 0.654 & 0.775 \\
\hline CAN & 0.315 & 0.369 & 0.477 & IND & 0.621 & 0.660 & 0.782 \\
\hline MEX & 0.440 & 0.506 & 0.646 & BRA & 0.517 & 0.571 & 0.704 \\
\hline JPN & 0.324 & 0.380 & 0.492 & AFR & 0.561 & 0.622 & 0.752 \\
\hline ANZ & 0.380 & 0.452 & 0.588 & MES & 0.456 & 0.534 & 0.666 \\
\hline EUR & 0.283 & 0.385 & 0.503 & LAM & 0.501 & 0.562 & 0.699 \\
\hline ROE & 0.488 & 0.563 & 0.697 & REA & 0.601 & 0.644 & 0.772 \\
\hline RUS & 0.443 & 0.532 & 0.672 & KOR & 0.428 & 0.479 & 0.600 \\
\hline ASI & 0.461 & 0.514 & 0.641 & IDZ & 0.572 & 0.621 & 0.757 \\
\hline
\end{tabular}

Source: USDA (2013)

It is worth noting that, as illustrated in Section 2, since the labor endowment (and population) of the representative consumer increases over time, the representative consumer of the model is indeed an aggregated consumer, which means that, on top of the income elasticity estimates for an individual $\eta_{i}$ presented in Equation (5), income elasticities for the model's representative consumer, denoted by $\eta_{i}$, should take into account the population growth. Taking total derivatives on aggregate consumption and budget to decompose changes and rearranging terms, we have:

$$
\eta_{i}^{\prime}=\frac{\eta_{i} \frac{d w}{w}+\frac{d p o p}{p o p}}{\frac{d w}{w}+\frac{d p o p}{p o p}}
$$

In Equation (15), $w$ is the budget (see Section 2) and pop is the population index of each region with the base year level normalized to unity (the regional index is dropped for succinctness).

Figure 4 illustrates the BAU projections for final consumption per capita as GDP per capita grows over time, starting from 2010 up to 2050. The results show that, with income elasticity adjustments, global food and crop consumption projections are lowered compared to those with a pure CES setting, which most likely overestimates the consumption levels as it fails to take into account the empirical evidence that income elasticities for food consumption are generally less than one. Using Reimer and Hertel's estimates, global food consumption in 2050 is $15.9 \%$ lower compared to the case with a pure CES setting. The projection is $23.6 \%$ lower if the USDA data were used, as shown in Figure 4a. Note that except for crop consumption, USDA elasticities lead to generally lower consumption of agriculture and food than projections using Reimer and Hertel's results, because the elasticities are lower. For global crop consumption (Figure 4b) the Reimer and Hertel and USDA produce similar results, which are around 30\% lower than the pure CES projection in 2050. This comes about because both studies have quite similar estimates for the income elasticities of crop consumption. Lastly, as Figure $4 \mathbf{c}$ shows, the projections for global livestock consumption based on Reimer and Hertel's estimates are very close to those with a pure CES setting, as Reimer and Hertel's income elasticity estimates for livestock 
products are generally higher (see Table 5 in Section 3). Using USDA's income elasticity estimates again produce lower projections (26.1\% lower in 2050 compared to the other two cases). As previously mentioned, Reimer and Hertel derived their numbers based on a particular functional form, the AIDADS demand system. USDA used a two-stage demand system.

Projections at the regional levels are presented for USA and CHN, as shown in Figure 4d through Figure 4i. In short, comparisons reveal that 1) income elasticity adjustments tend to lower projections for food, crop, and livestock consumption levels; 2) the USA has lower growth rates for the consumption levels of these products compared to those of CHN, since the USA has lower income elasticity estimates; and 3) except for crop consumption in the USA, projections based on USDA estimates are lower as the underlying elasticity numbers of USDA are lower. 


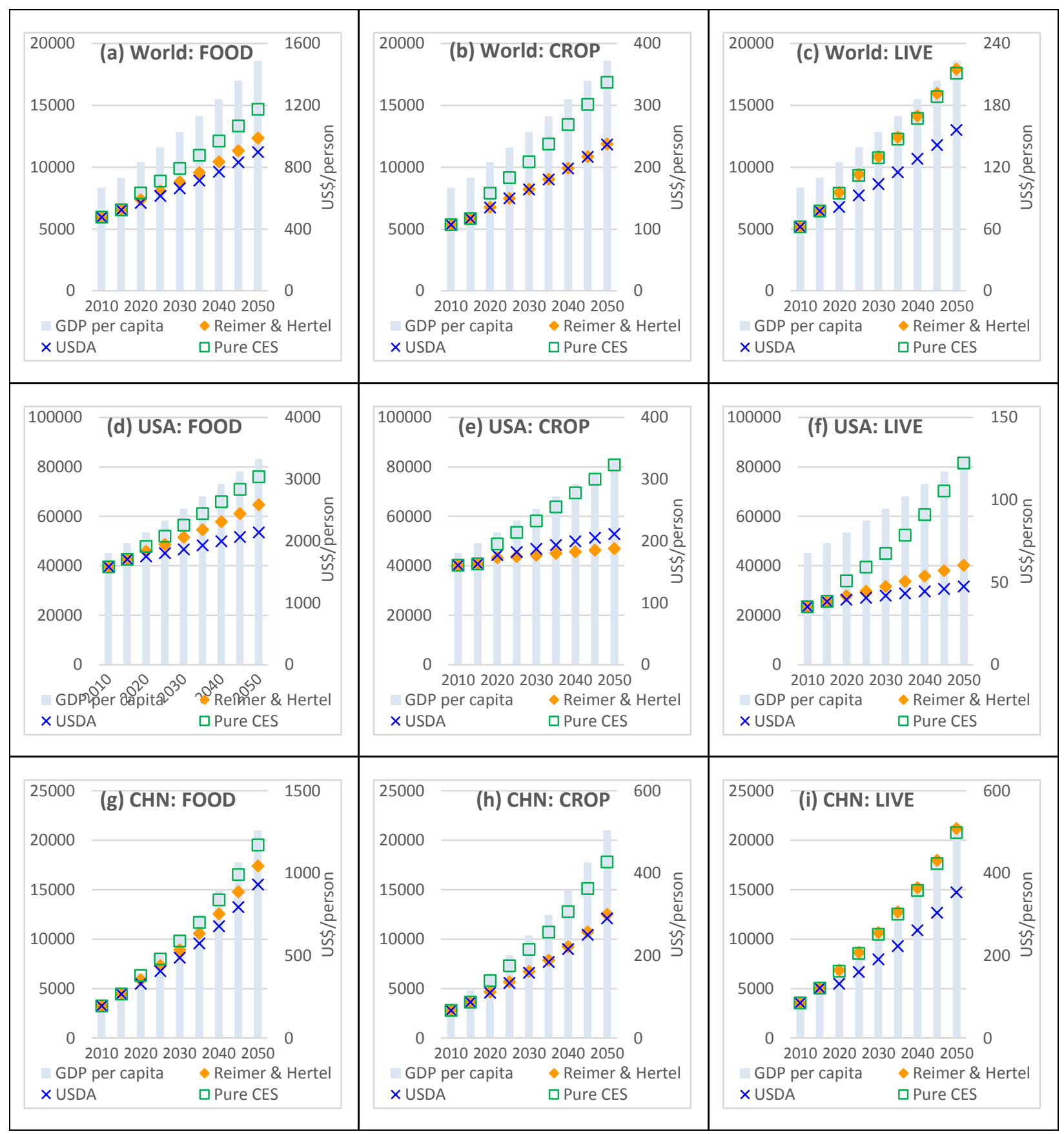

Figure 4. Final consumption projections for food, crop, and livestock products.

\subsection{Response to a greenhouse gas mitigation policy}

As discussed earlier, different parameter sets can equally fit the historical data, and even generate a similar BAU forecast but can then behave differently in response to a policy shock. Unfortunately, there is no good historical evidence on how the economy would respond to significant GHG mitigation policy as we have not observed one. Moreover, mitigation is likely to 
involve the need for widespread adoption of new technologies that have not been widely used before. To assess the model's policy response, we consider a sample greenhouse gas mitigation policy through the 2050 horizon, that continued would keep the world within a two-degree warming target. The IPCC has set forth a carbon budget that approximates, on a century time scale, allowable cumulative emissions that, at median climate response, is associated with $2^{\circ} \mathrm{C}$ warming (IPCC, 2014b). A path through 2100 consistent with that budget is shown in Figure 5.

We implement this path through 2050 in our model. To do so, we impose identical percentage reduction caps (from 2015 emissions levels) in each region. The sample policy starts from 2020, cutting $\mathrm{CO}_{2}$ emissions to $50 \%$ of 2015 level by 2050. Other non- $\mathrm{CO}_{2}$ GHGs are taxed at the same GWP-equivalent (IPCC, 2014a), endogenously determined, regional carbon prices resulting from these caps. The sample policy imposed here is not meant to reflect political feasibility, and as formulated is not necessarily a least-cost policy as the GHG prices vary among regions and are not necessarily inter-temporally optimized. It simply allows us to examine the model performance under an ambitious GHG target that is the stated goal of international negotiations.

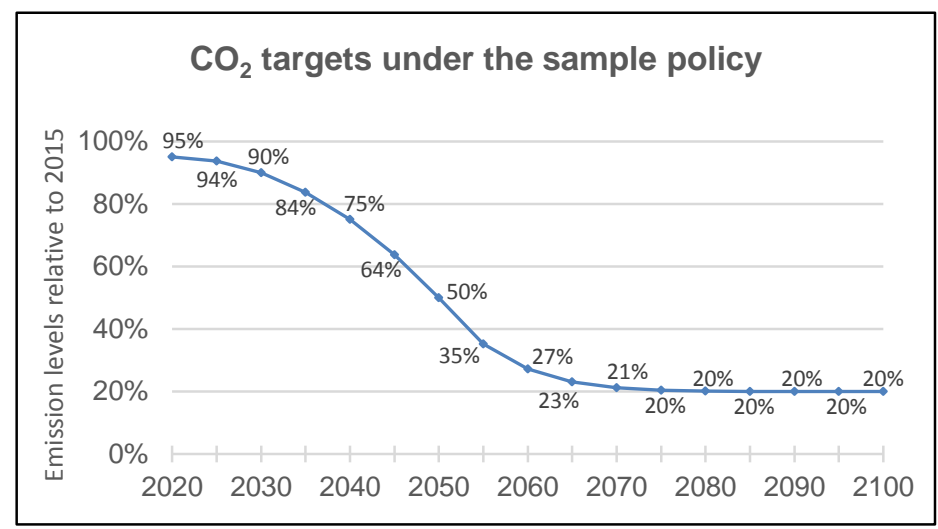

Figure 5. $\mathrm{CO}_{2}$ targets under the sample policy.

The implications of the policy for the world economy are a reduction in global GDP by 2050 of about $\$ 14.5$ billion (from about $\$ 177.8$ to $\$ 163.1$ billion - or about 8.3\%) (Figure 6). The cost over the considered time horizon is a reduction of $3.0 \%$ in net present value terms compared to BAU, assuming a 5\% discount rate. This is purely the mitigation costs, and does not include estimates of benefits of avoided climate damage or possibly ancillary benefits of avoided air pollution or other costs non-market costs associated with fossil fuel use. For a discussion of efforts to quantify benefits in the EPPA-IGSM framework see Reilly et al., 2013. 


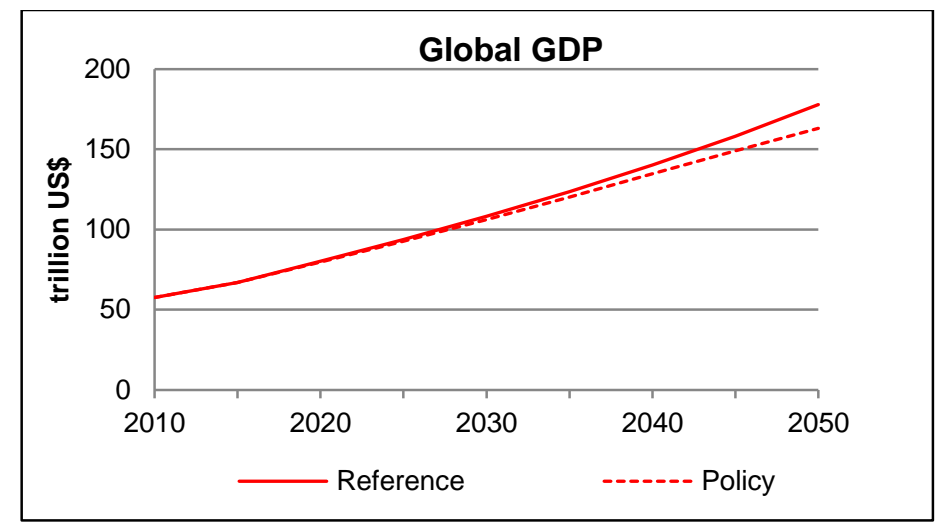

Figure 6. Global GDP: BAU vs. Policy.

Since energy use patterns are closely related to emissions, we present model outputs for total primary energy demand levels in Figure 7a (for the BAU case) and Figure 7b (for the policy case). For the BAU simulation, compared to the 2010 level, the global GDP level is tripled (from around $\$ 57.6$ trillion to $\$ 177.8$ trillion in 2007 US dollars) by 2050 . The global primary energy demand increases at a much slower pace by $80.1 \%$ (from 497.7 EJ in 2010 to 896.1 EJ in 2050) due to energy efficiency improvements and changes in industrial structure. Nevertheless, the projection shows that the global economy during the same period will continue to rely heavily on fossil fuels with an increasing share of gas (23.6\% to $25.4 \%)$, while the shares of coal (28.7\% to $28.3 \%$ ) and oil (33.8\% to $34.2 \%$ ) remain almost unchanged. Under this scenario, the roles of hydro, biofuels, other renewables (wind and solar), and nuclear power do not change much over time.

With the sample policy, results shown in Figure 7b suggest that a cut in fossil fuels consumption is needed to achieve the policy goal (from 428.3 EJ in 2010 to 317.7 EJ in 2050). Under this scenario, as expected, the roles of hydro, biofuels, and other renewables become more important, with the sum of shares rising from about $8.7 \%$ in 2010 to $24.0 \%$ in 2050.

Additionally, the share of nuclear power also increases, from around $5.2 \%$ in 2010 to $9.0 \%$ in 2050 .

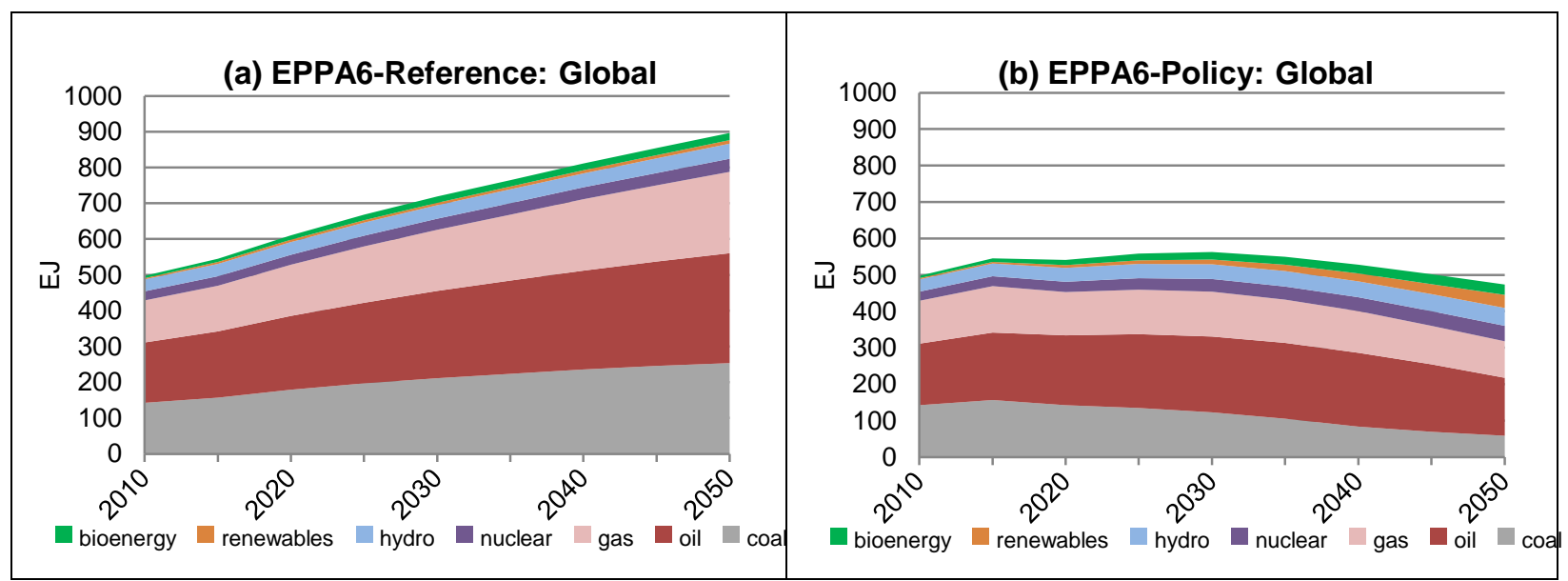

Figure 7. Total primary energy demand: BAU vs. Policy. 
Figure 8 presents the energy-related $\mathrm{CO}_{2}$ emissions. In the BAU scenario, compared to the 2010 levels, the emissions increase by $82.7 \%$ by 2050 , which are directly related to the consumption of fossil fuels that increases by $84.0 \%$ during the same period. The slightly slower growth path of the emissions is a result of the slight increase in the share of gas, as discussed previously. With the sample policy, the emission level will be cut by almost $70 \%$ relative to the reference level in 2050.

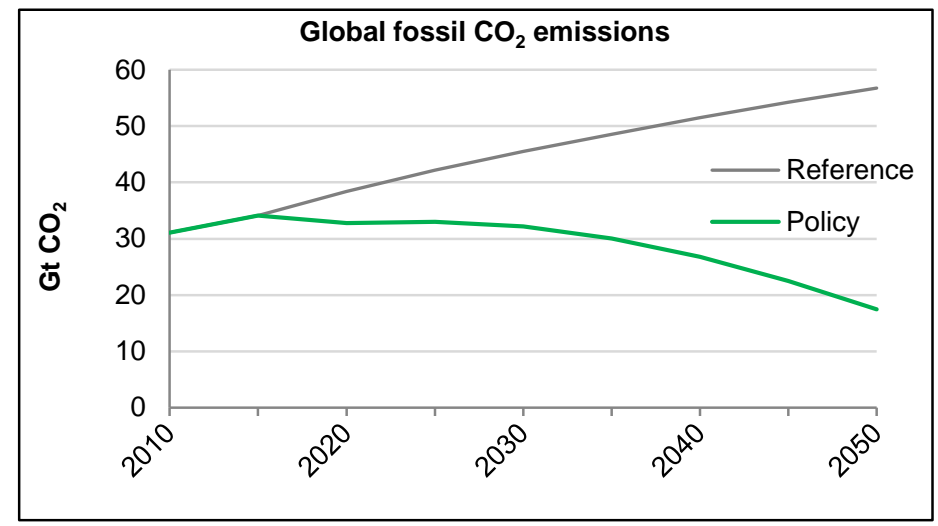

Figure 8. Global fossil $\mathrm{CO}_{2}$ emissions.

\subsection{Sensitivity Analyses}

Long-term projections for future emissions and $\mathrm{CO}_{2}$ prices are closely related to energy use levels, which are in turn determined by many other parameters with values that are subject to uncertainty. A classic approach to assess the uncertainty in model results is to test their sensitivity to key parameters. For instance, Paltsev et al. (2005) and Webster et al. (2003) point out that economic growth is one of the most important drivers for energy use and emissions. Webster et al. (2008b) conducted an extensive sensitivity and uncertainty analysis with a previous version of EPPA. While an extensive uncertainty analysis is beyond the scope of this paper, work with previous versions of the model have identified key variables affect different projected variables. We thus present a sensitivity analysis focusing on those parameters that have proven to be important determinants of energy use and policy costs in previous work. These include: 1) BAU GDP growth; 2) Energy productivity growth; 3) elasticities of substitution between energy and non-energy inputs; 4) the fraction of malleable capital that becomes nonmalleable at the end of each period; and 5) constrained nuclear power expansion. The nuclear sensitivity involves a potentially key technology for GHG mitigation. While many developing countries such as China and India appear willing to expand nuclear power (World Nuclear Association, 2015), for others, the accident history with nuclear, particularly after the Fukushima accident in Japan has led to moves to stop further development or phase out existing capacity. We compare the structure of generation mix and GDP impact with and without the constraint on nuclear expansion under the sample two-degree policy scenario. 
For the first three parameters presented in the analysis below, we consider a $20 \%$ range of deviation from the base values. In Figure 9, we use "base" to denote the adoption of parameter values with the original EPPA6 numbers, "high" and "low" refers to results where the considered parameter value is $20 \%$ higher or lower than the base level. As Figure 9 shows, the projected BAU global $\mathrm{CO}_{2}$ emissions in 2050 are most sensitive to GDP growth assumptions.

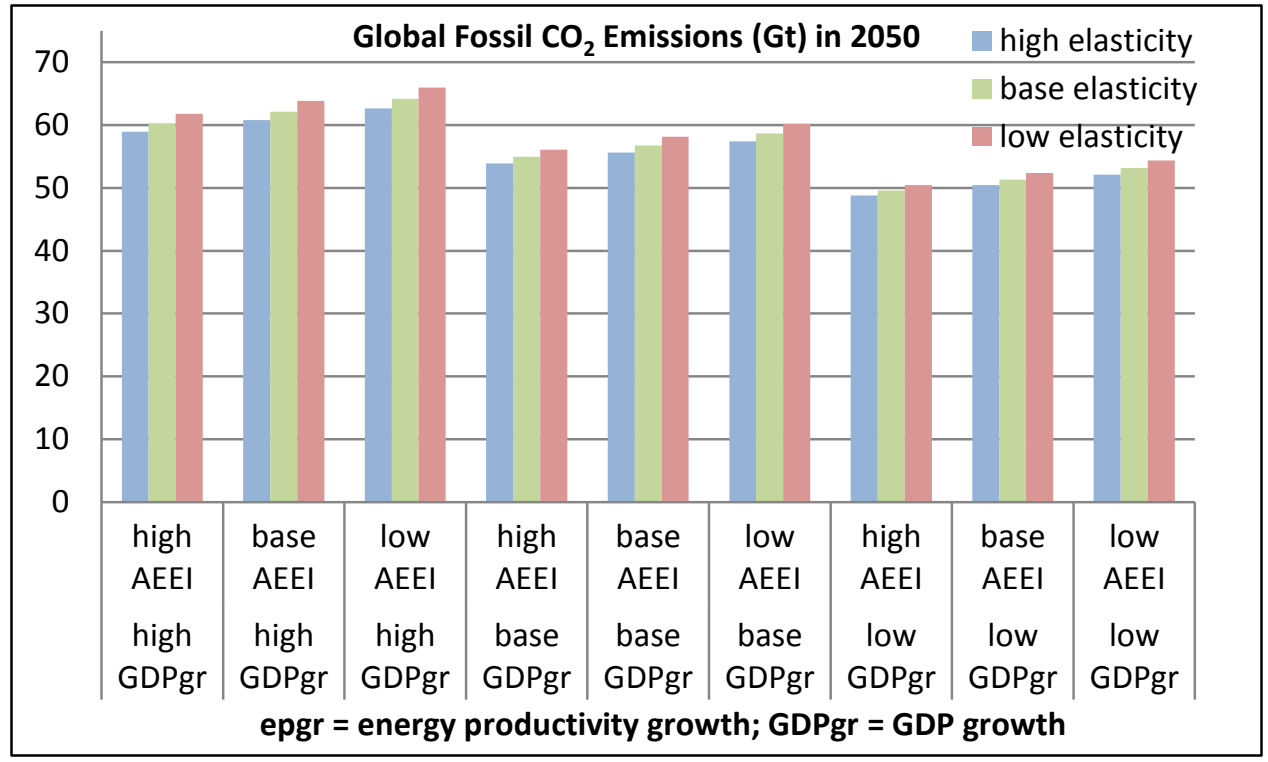

Figure 9. $\mathrm{BAU}$ global combusted $\mathrm{CO}_{2}$ emissions under different assumptions.

For instance, holding the other two parameter values at their base levels, if we normalize the global emissions to one, the range of emissions due to different GDP growth levels is between 0.90 and 1.09, and ranges of emissions due to various energy productivity growth levels and elasticity assumptions are in the 0.97-1.03 and 0.98-1.02 ranges, respectively. Emissions are less sensitive to the assumption for energy productivity growth due to the "rebound effect" of efficiency improvement. More specifically, the non-price driven efficiency improvement lowers demand for energy and thus the energy price, but the cheaper price encourages energy use and so the overall energy saving and reduced emissions are not as high as one might expect. Applying the same rationale in the reverse direction explains the result for a decrease in energy productivity growth. On the other hand, the substitution elasticity between the energy and non-energy input can capture the price driven efficiency improvement. For instance, to produce the same output, with a higher elasticity level, it will be easier to use more capital, labor, and other intermediate inputs to replace the energy input when the relative price of energy increases. We find that, at the global level, emissions are least sensitive to changes in substitution elasticities. The caution here is that the importance of the substitution elasticity also interacts with the projected price path of energy. If the relative prices of energy were projected to be stable over time, then the elasticity would have little or no effect. Another caveat is that the $20 \%$ deviations are arbitrary. If, for example, we were far more certain about energy productivity growth or GDP growth than about elasticities, then the uncertainty in 
elasticities could cause larger variation in outcomes even though the sensitivity to a fixed range is less. Nevertheless, these sensitivity analyses are informative to study the model response.

Figure 10 presents $\mathrm{BAU} \mathrm{CO} 2$ emissions and $\mathrm{CO}_{2}$ prices under the sample policy for selected regions. We find that up to 2050, deviations of emissions projections from the base case (the original setting of EPPA6) are mostly less than $10 \%$ under the considered sensitivity analysis. The only exception is the case of CHN under the highest GDP growth assumptions, which result in slightly higher deviations from the base case (in the range of 0.90-1.10 if we normalize the base case emissions level in 2050 to one). Not surprisingly the range outcomes grows the further in the future the projection. As is the case for the world as whole, different energy productivity growth and elasticity levels have smaller effects on BAU emissions. Also, compared to the cases of other regions, changes in China's BAU GDP growth have higher impacts on its emissions since the base case GDP growth levels of CHN are the highest among all of the modeled regions. Figure 10 also presents the projected $\mathrm{CO}_{2}$ prices for selected regions under the sample policy. The higher $\mathrm{CO}_{2}$ prices of EUR reflect the fact that EUR is less coal-intensive and thus less carbon-intensive from the beginning, and therefore has fewer options to decarbonize. In the US and China a simple shift to natural gas can achieve significant reductions in emissions from electricity generation. If we use the emissions to GDP ratio as the proxy for the average carbon intensity level of economic activities, the base year number of EUR is $0.21 \mathrm{Kg} / \mathrm{US} \$$, which is much lower than those for USA (0.41 Kg/US\$) and CHN (1.69 Kg/US\$). Similarly, we also observe that $\mathrm{CHN}$, which is the most carbon intensive among the three regions from the beginning, has the lowest projected $\mathrm{CO}_{2}$ prices over time.

The projected $\mathrm{CO}_{2}$ prices may also change due to uncertainties in those considered parameters. As expected, for each region, different GDP growth assumptions contribute to a higher variation in $\mathrm{CO}_{2}$ prices, as uncertainty in economic growth accounts for more variations in emissions. Uncertainties in energy productivity growth and substitution elasticities also affect $\mathrm{CO}_{2}$ price projections. Higher energy productivity growth levels reduce fossil fuels consumption and emissions, and therefore lower $\mathrm{CO}_{2}$ prices. On the other hand, higher elasticity levels makes it easier to switch from burning fossil fuels (which incurs carbon penalties) to using other nonenergy inputs, and lower elasticity levels make the switch for avoiding the carbon penalty trickier. The finding suggests that in addition to uncertainty in future economic growth, careful research to characterize energy productivity growth and the ability of energy and non-energy substitution is crucial in reducing the uncertainty in $\mathrm{CO}_{2}$ price projections. 


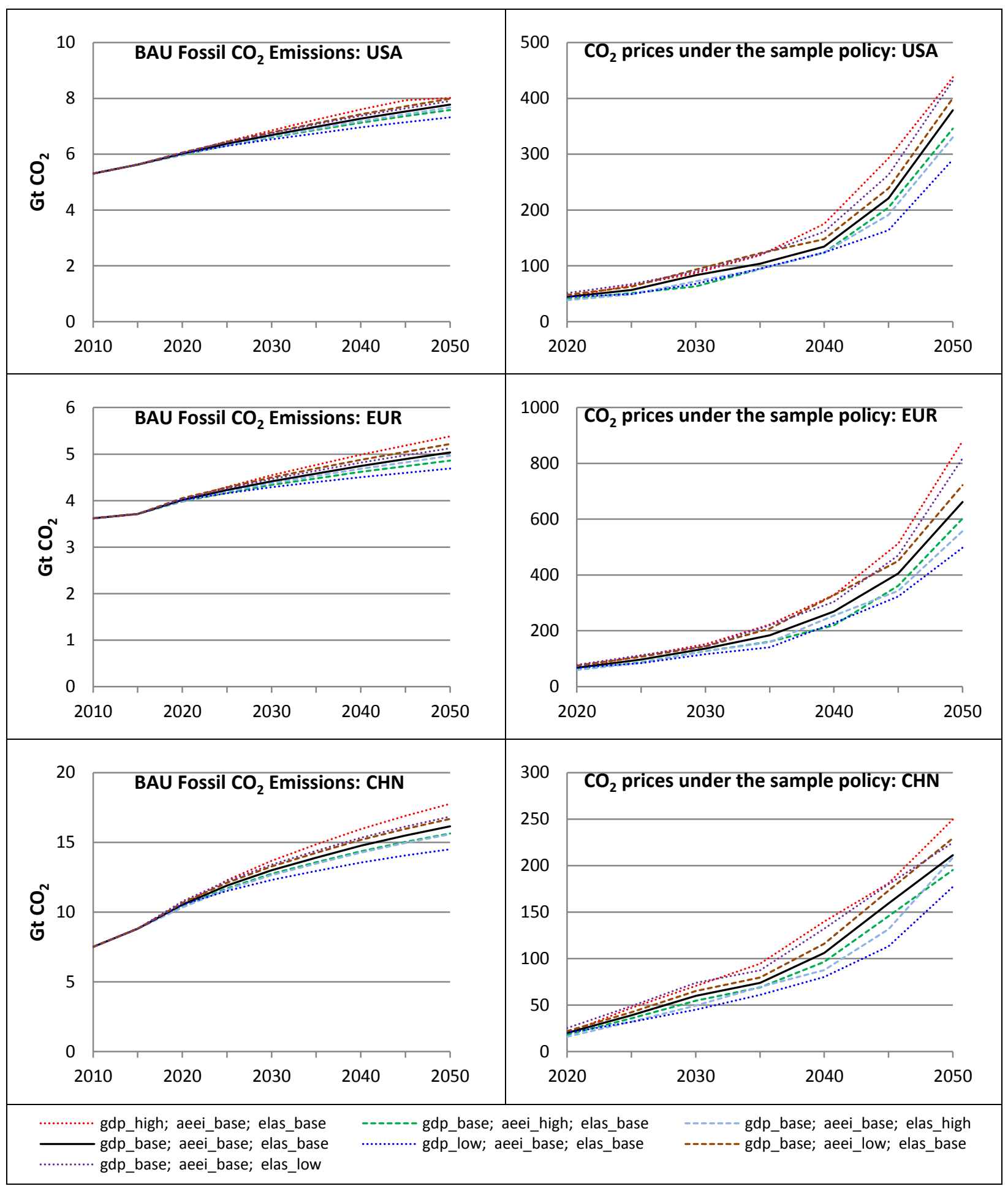

Figure 10. $\mathrm{BAU}$ combusted $\mathrm{CO}_{2}$ emissions and $\mathrm{CO}_{2}$ prices under the sample policy.

We continue to explore how sensitive the fossil $\mathrm{CO}_{2}$ emissions are due to different values of $\theta$, the fraction of malleable capital that becomes non-malleable at the end of each period. Similar to Paltsev et al. (2005), the default setting $\theta=0.7$ for power sector and $\theta=0.3$ for all other sectors. In Figure 11, we multiply a positive coefficient on each sector's $\theta$, and demonstrate that 
the higher the $\theta$, the higher the emissions. This is because for each sector, if more malleable capital becomes non-malleable in each period, the overall energy efficiency of that sector would decrease, as there is no energy productivity growth for production activities using non-malleable capital (see Section 3). The higher energy consumption level due to lower efficiency explains higher emissions levels. The result in Figure 11 shows that as each sector's $\theta$ changes, while fossil $\mathrm{CO}_{2}$ emissions would change in the expected direction, the overall deviation in cumulative emissions levels for 2010 to 2050 will stay within $1.0 \%$ with up to $40 \%$ deviation in the default $\theta$ values.

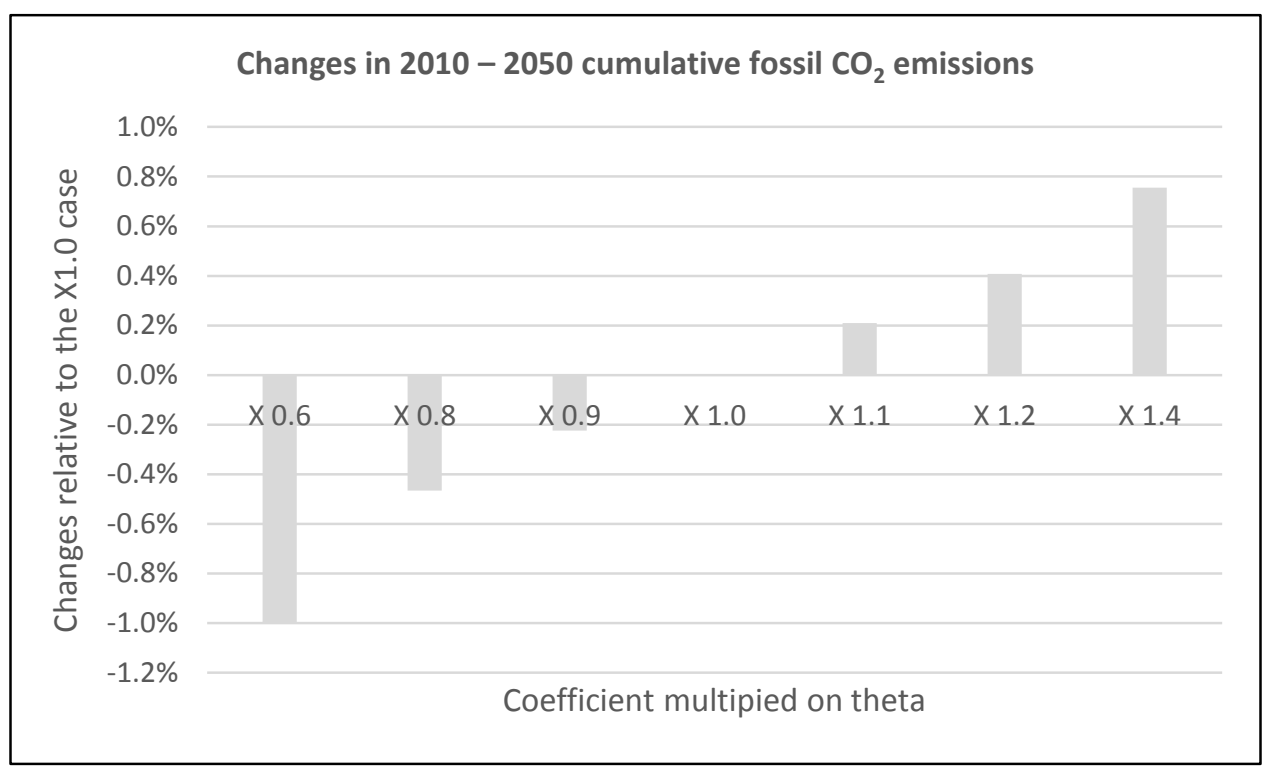

Figure 11. Changes in fossil $\mathrm{CO}_{2}$ emissions due to different $\theta$ values.

Figure 12 compares the power sector generation mix at the global level under three scenarios: reference, sample policy, and sample policy with a nuclear expansion constraint. In the first two scenarios, there is no policy-driven constraint on nuclear expansion, which is the default setting. In the constrained nuclear scenario, nuclear output for each region is capped at the 2020 level. Figure 12a shows that in the reference scenario, there is no drastic change in the generation mix through 2050. The output of nuclear power increases from around $2900 \mathrm{TWh} / \mathrm{year}$ (current level) to over $4300 \mathrm{TWh}$ /year in 2050 but nuclear share actually falls slightly from $13.3 \%$ to $10.1 \%$ during the same period. Fossil generation options continue to operate without carbon capture and storage (CCS) as there is no carbon policy in the reference scenario.

With the same assumption for nuclear power as Figure 10a, Figure 12b presents the generation mix under the sample policy. It shows that the output of nuclear power would increase to around $5032 \mathrm{TWh} /$ year in 2050 and at that level accounts for about $20 \%$ of global generation. With the sample policy, CCS is introduced to fossil generation as well. Figure 12c considers the case where the sample policy is imposed, but the nuclear expansion is not allowed. The comparison between Figure 12b and Figure 12c shows that with the constraint on nuclear expansion, the share of each non-nuclear option increases. Figure 13 reveals that under the 
sample policy, while the GDP impact with the nuclear constraint will be somewhat higher than that without the constraint, the additional GDP reduction due to the nuclear constraint is relatively small.

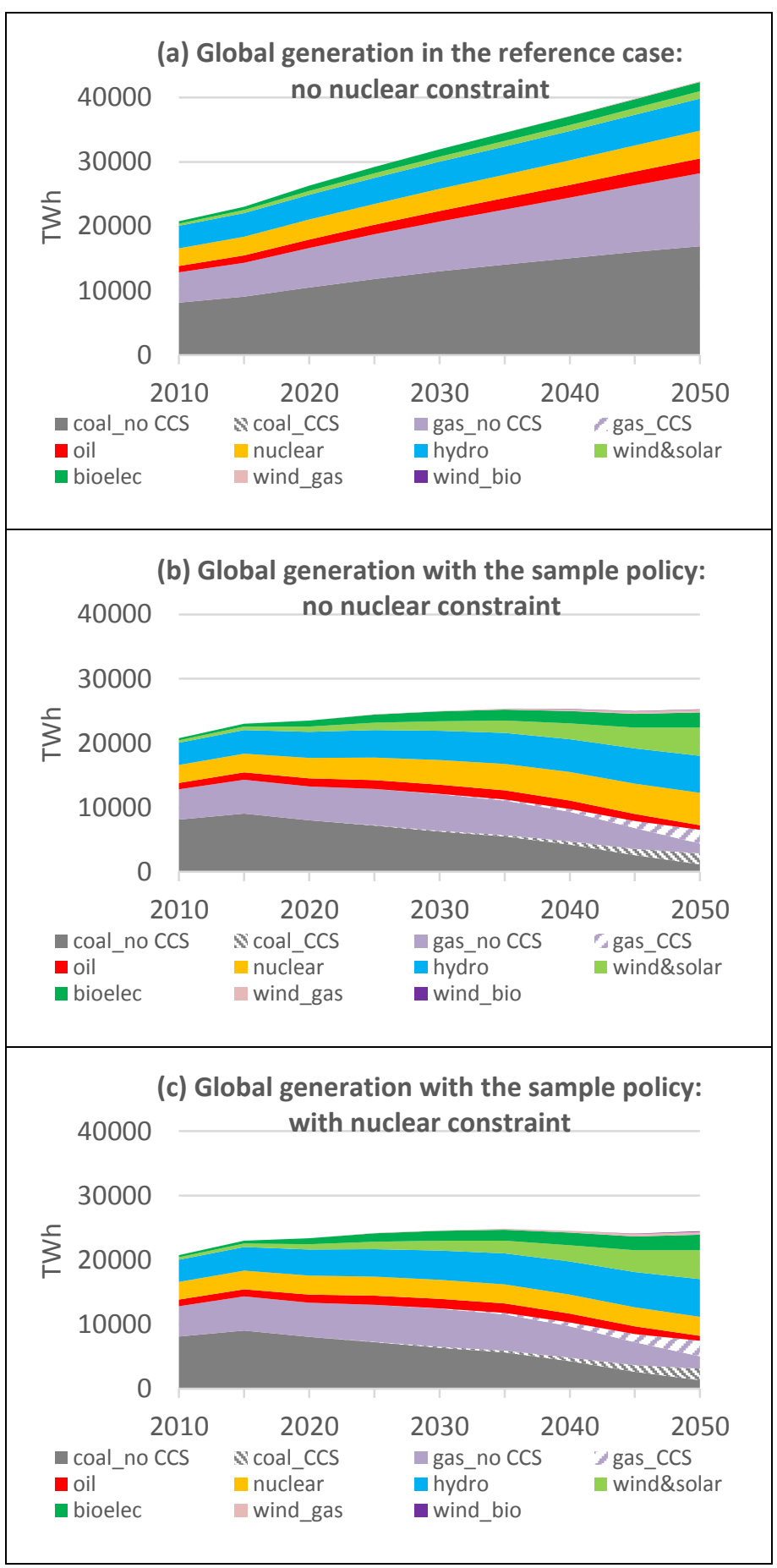

Figure 12. Power sector general mix under the policy scenario. 


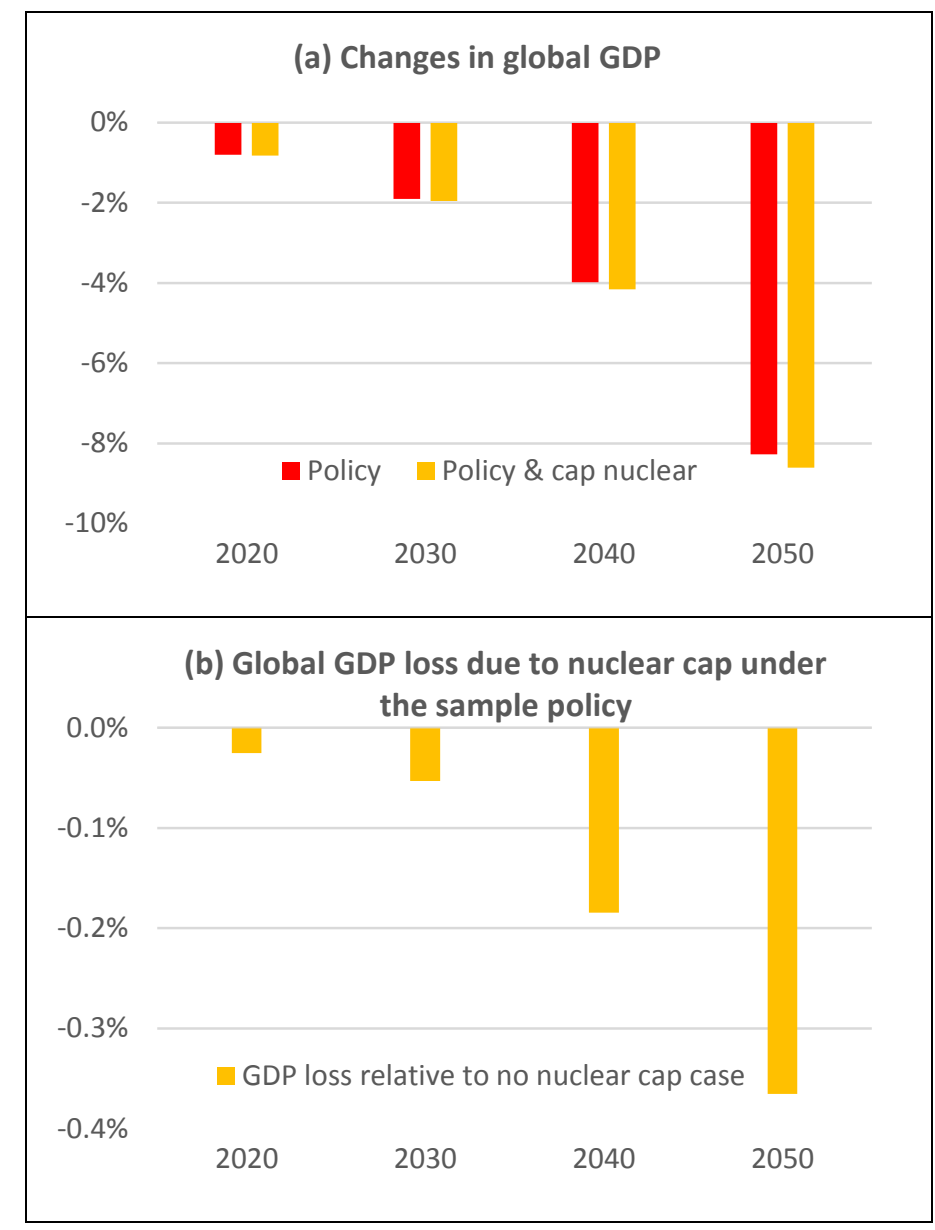

Figure 13. Global GDP loss under the sample policy.

These various sensitivity results illustrate some key determinants of policy cost and technology outcome that depend on key parameters of the model such as substitution elasticities and the malleability of capital which are known with uncertainty, the basic GDP forecast, and elements of the policy and technology environment such as whether nuclear power will be allowed to expand unfettered or will face restrictions.

\section{CONCLUSIONS}

Large scale CGE models have been used extensively for energy and environmental policy analyses. In addition, they are often crucial components of various integrated assessment frameworks, which are used for studying interdisciplinary questions within broader contexts. However, a growing concern is whether these models produce reliable projections. This study aims to tackle that question in several ways: First, we provide details on the data, structure, and features in the most recent version of the EPPA model. We then run several tests of the model comparing its projections against history, benchmarking it against other projections, comparing it to previous forecasts and different estimates of key elasticities, and conducting a sensitivity analysis of results to parameters to which these are known to be sensitive. We believe these tests 
at least help to understand the basic responsiveness of the model and that comparable efforts for other models will be valuable as well.

Any long-term projection from an energy-economic model will inevitably involve distinct aspects of uncertainty, including factors such as (but not limited to) economic growth, energy productivity improvement, and substitution elasticity between energy and non-energy inputs. As a result, in this study, we demonstrate how changes in the values of these parameters may affect $\mathrm{CO}_{2}$ emissions levels and prices. We also demonstrate how sensitive $\mathrm{CO}_{2}$ emissions are due to changes in $\theta$, the portion of malleable capital that becomes non-malleable at the end of each period, and study the consequence of imposing a nuclear expansion constraint along with a sample policy toward a two-degree warming target. In addition, we explore the implications of adopting non-homothetic preferences on the projections for food and agricultural products' consumption, which are also crucial as numerous studies have found the evidence against the assumption of an income elasticity of one for the consumption of these products.

With development and documentation of this core version of the model, further advancement of the model can proceed to expand the range of scenarios the model can reasonably address and the issues it can explore. These include 1) A comprehensive representation for land-use change: following the framework developed by Gurgel et al. (2007), economic incentives for land-use conversions as well as $\mathrm{CO}_{2}$ emissions from the land-use changes will be considered; 2) More detailed representation of biofuels and biomass energy, including first generation biofuels: as presented by Gitiaux et al. (2012) and Winchester and Reilly (2015), different biofuels production activities will be identified, each with its own land-use and carbon footprint implications and the possibility to use biomass energy more broadly in the economy with carbon capture and storage options; 3) Refined oil sectors details: as in Ramberg (2015) and Choumert et al. (2006), the single refined oil product of GTAP 8 can be disaggregated into different petroleum products with various uses and emissions factors to better evaluate diesel, gasoline, and other refined product demands; and 4) Add household transportation details: based on Karplus et al. (2013b), household owned-supplied transportation (service from private automobiles) will be disaggregated by age and powertrains to improve policy analyses such as fuel efficiency requirements on automobiles.

A significant challenge for models of this type is the interest in very low carbon emissions scenarios. Since the world has relied heavily on fossil energy for more than 150 years, we have very little evidence of how a modern economy, that will likely be many times larger than todays, can operate while emitting a very small fraction of the carbon emissions we emit today. There are small economies with abundant geothermal or hydro power that appear to operate with low carbon emissions, but even in these cases it is possible these economies are still importing carbon intensive products from abroad. On the other hand, for a CGE model such as EPPA, where production functions have the property that all inputs are necessary inputs, it is important to carefully develop alternative technologies that ultimately can completely eliminate fossil fuel inputs. In developing EPPA we have focused on electricity production, transportation, and non$\mathrm{CO}_{2}$ greenhouse gases, but as those sectors are cleaned up to get to very low economy-wide 
emissions, further focus on other sectors of the economy is needed. This requires projection well outside the experience of modern economies.

\section{Acknowledgments}

We gratefully acknowledge the financial support for this work provided by the MIT Joint Program on the Science and Policy of Global Change through a consortium of industrial and foundation sponsors and Federal awards, including the U.S. Department of Energy, Office of Science under DE-FG02-94ER61937 and the U.S. Environmental Protection Agency under XA83600001-1. For a complete list of sponsors and the U.S. government funding sources, please visit http://globalchange.mit.edu/sponsors/all. We appreciate contribution and inputs from Thomas Rutherford, Qudsia Ejaz, Kyung-min Nam, and Anna Agarwal during various stages of model development. We are thankful for comments from referees, editor, Jamie Bartholomay, Paul Kishimoto, Giacomo Schwarz, participants of the $17^{\text {th }}$ GTAP Conference in Senegal, and the MIT EPPA meeting. All remaining errors are our own.

\section{REFERENCES}

Addessi, W., 2014: Preference shifts and change of consumption composition, Economic Letters, 125(1): 14-17.

Armington, P.S., 1969: A Theory of Demand for Products Distinguished by Place of Production. International Monetary Fund Staff Papers 16: 159-176.

Babiker, M.H., A. Gurgel, S. Paltsev, and J. Reilly, 2009: Forward-looking versus recursivedynamic modeling in climate policy analysis: A comparison. Economic Modelling 26(6): 1341-1354.

Babiker, M.H., J.M. Reilly, M. Mayer, R.S. Eckaus, I. Sue Wing and R.C. Hyman, 2001: The MIT Emissions Prediction and Policy Analysis (EPPA) Model: Revisions, Sensitivities, and Comparisons of Results. MIT JPSPGC Report 71, Cambridge, MA (http://globalchange.mit.edu/files/document/MITJPSPGC_Rpt71.pdf).

Bechtel Power Corporation, 1981: Coal-fired Power Plants Capital Cost Estimates. Report prepared for the Electric Power Research Institute. San Francisco, CA 94119.

Boden, T.A., G. Marland, and R.J. Andres, 2010: Global, Regional, and National Fossil-Fuel $\mathrm{CO}_{2}$ Emissions. Carbon Dioxide Information Analysis Center, Oak Ridge National Laboratory, U.S. Department of Energy, Oak Ridge, Tenn., USA.

Bovenberg, A.L. and L.H. Goulder, 1996: Optimal Environmental Taxation in the Presence of Other Taxes: General-Equilibrium Analyses. American Economic Review 86(4): 985-1000.

Choumert, F., S. Paltsev and J. Reilly, 2006: Improving the Refining Sector in EPPA. MIT JPSPGC Technical Note 9, July, 56 p. (http://globalchange.mit.edu/files/document/MITJPSPGC_TechNote9.pdf).

Cossa, P., 2004: Uncertainty Analysis of the Cost of Climate Policies. Master of Science Thesis, Technology and Policy Program, MIT, Cambridge, Massachusetts.

Empresa de Pesquisa Energética (EPE), 2007: Plano Nacional de Energia 2030. Empresa de Pesquisa Energética, Brasilia, Brazil (http://www.epe.gov.br/PNE/20080512_2.pdf). 
Energy Information Administration (EIA), 2013a: How Old Are U.S. Power Plants? U.S. Energy Information Administration, Washington, D.C.

(http://www.eia.gov/energy_in_brief/article/age_of_elec_gen.cfm).

Energy Information Administration (EIA), 2011: Age of electric power generators varies widely. Today in Energy. U.S. Energy Information Administration, Washington, D.C.

(http://www.eia.gov/todayinenergy/detail.cfm?id=1830).

Energy Information Administration (EIA), 2013b: Annual Energy Outlook 2013: With

Projections to 2040. U.S. Energy Information Administration, Washington, D.C.

(http://www.eia.gov/forecasts/aeo/MT_electric.cfm).

Energy Information Administration (EIA), 2010: Annual Energy Outlook 2010: With Projections to 2035. U.S. Energy Information Administration, Washington. D.C.

(http://www.eia.gov/oiaf/aeo/pdf/0383\%282010\%29.pdf)

European Commission (EC), 2011: Emission Database for Global Atmospheric Research (EDGAR), release version 4.2. Joint Research Centre (JRC)/Netherlands Environmental Assessment Agency (PBL), EC (http://edgar.jrc.ec.europa.eu).

Ferris, M. C. and J. S. Pang, 1997: Engineering and Economic Applications of Complementarity Problems. SIAM Review, 39(4): 669-713.

Gitiaux, X., S. Paltsev, J. Reilly and S. Rausch, 2012: Biofuels, Climate Policy, and the European Vehicle Fleet. Journal of Transport Economics and Policy 46(1): 1-23.

Global Trade Analysis Project (GTAP), 2013: GTAP Databases: GTAP 8 Database. Center for Global Trade Analysis, Department of Agricultural Economics, Purdue University, March. (https://www.gtap.agecon.purdue.edu/databases/v8/).

Gordon, R. J., 2012: Is U.S. Economic Growth Over? Faltering Innovation Confronts the Six Headwinds, National Bureau of Economic Research Working Paper 18315, Cambridge, MA (http://www.nber.org/papers/w18315).

Guillo', M.D., C. Papageorgiou, and F. Perez-Sebastian, 2011: A unified theory of structural change. Journal of Economic Dynamics \& Control 35: 1393-1404.

Gurgel, A., J. Reilly, and S. Paltsev, 2007: Potential Land Use Implications of a Global Biofuels Industry. Journal of Agricultural \& Food Industrial Organization 5(2): Article 9.

Haque, M.O., 2005: Income Elasticity and Economic Development: Methods and Applications. 277 p., Springer.

Intergovernmental Panel on Climate Change (IPCC), 2014a: Fifth Assessment Report. IPCC Secretariat, World Meteorological Organization, Geneva, Switzerland.

Intergovernmental Panel on Climate Change (IPCC), 2014b: Climate Change 2014 Synthesis Report: Summary for Policymakers. IPCC Secretariat, World Meteorological Organization, Geneva, Switzerland.

International Energy Agency (IEA), 2012: World Energy Outlook. International Energy Agency, Paris, France (http://www.worldenergyoutlook.org/publications/weo-2012/).

International Energy Agency (IEA), 2014: World Energy Outlook. International Energy Agency, Paris, France (http://www.worldenergyoutlook.org/publications/weo-2014/). 
International Monetary Fund (IMF), 2013: World Economic and Financial Surveys: World Economic Outlook Database, Washington, D.C., USA (http://www.imf.org/external/pubs/ft/weo/2013/01/weodata/download.aspx).

Jacoby, H. D. and Y.-H.H. Chen, 2014: Expectations for a New Climate Agreement. MIT JPSPGC Report 264, August, 24 p. (http://globalchange.mit.edu/files/document/MITJPSPGC_Rpt264.pdf).

Jacoby, H. D., F. M. O’Sullivan, and S. Paltsev, 2012: The Influence of Shale Gas on U.S. Energy and Environmental Policy. Economics of Energy \& Environmental Policy 1(1): 37-51.

Karplus, V.J., S. Paltsev, M. Babiker and J.M. Reilly, 2013a: Should a vehicle fuel economy standard be combined with an economy-wide greenhouse gas emissions constraint? Implications for energy and climate policy in the United States. Energy Economics 36: 322-333.

Karplus, V.J., S. Paltsev, M. Babiker and J.M. Reilly, 2013b: Applying engineering and fleet detail to represent passenger vehicle transport in a computable general equilibrium model. Economic Modelling 30: 295-305.

Lanz, B., S. Dietz T. Swanson, 2014: Global population growth, technology, and Malthusian constraints: A quantitative growth theoretic perspective, draft manuscript, March

Markusen, J. and T. F. Rutherford, 2004: Getting Started with GAMS/MCP: Introduction to Computable General Equilibrium Modeling with GAMS and MPSGE. University of Colorado, Boulder (http://www.mpsge.org/gettingstarted.pdf).

Markusen, J., 2006: Extension of the Simple Model. University of Colorado, Boulder (http://spot.colorado.edu/ markusen/teaching_files/applied_general_equilibrium/GAMS/ch2.pdf).

Markusen, J., 2013: General-Equilibrium Modeling using GAMS and MPS/GE: Some Basics. University of Colorado, Boulder (http://spot.colorado.edu/ markusen/teaching_files/applied_general_equilibrium/GAMS/ch1.pdf).

Mathiesen, L., 1985: Computation of Economic Equilibra by a Sequence of Linear Complementarity Problems. Mathematical Programming Study 23: 144-162.

McCarl, B., A. Meeraus, P. van der Eijk, M. Bussieck, S. Dirkse, P. Steacy, and F. Nelissen, 2014: McCarl Expanded GAMS User Guide: Version 24.3 (http://www.gams.com/mccarl/mccarlhtml/gams_user_guide_2005.htm).

MIT Joint Program, 2013: 2013 Energy and Climate Outlook, MIT Joint Program on the Science and Policy of Global Change, Cambridge, MA.

Morris, J., J. Reilly, and Y.-H. H. Chen, 2014: Advanced Technologies in Energy-Economy Models for Climate Change Assessment. MIT JPSPGC forthcoming report, $29 \mathrm{p}$.

Nam, K.-M., C.J. Waugh, S. Paltsev, J.M. Reilly and V.J. Karplus, 2013: Carbon co-benefits of tighter $\mathrm{SO}_{2}$ and $\mathrm{NO}_{x}$ regulations in China. Global Environmental Change 23(6): 1648-1661, 2013.

Narayanan, G., Badri, T. W. Hertel and T. L. Walmsley, 2012: GTAP 8 Data Base Documentation - Chapter 1: Introduction. Center for Global Trade Analysis, Department of Agricultural Economics, Purdue University, March (https://www.gtap.agecon.purdue.edu/resources/download/5673.pdf). 
Paltsev, S., V. Karplus, Y.-H.H. Chen, I. Karkatsouli, J.M. Reilly and H.D. Jacoby, 2014a: Regulatory Control of Vehicle and Power Plant Emissions: How Effective and at What Cost? Climate Policy, forthcoming.

Paltsev S., Y.-H.H. Chen, J. Reilly, J. Morris, V. Karplus, A. Gurgel, N. Winchester, P. Kishimoto, E. Blanc, and Q. Ejaz, 2014b: The MIT Emissions Prediction and Policy Analysis (EPPA) Model: Version 5. MIT JPSPGC forthcoming report.

Paltsev, S., H.D. Jacoby, J.M. Reilly, Q.J. Ejaz, J. Morris, F. O'Sullivan, S. Rausch, N. Winchester and O. Kragha, 2011: The Future of U.S. Natural Gas Production, Use, and Trade. Energy Policy 39(9): 5309-5321.

Paltsev S., J. Reilly, H. Jacoby, R. Eckaus and J. McFarland and M. Babiker, 2005: The MIT Emissions Prediction and Policy Analysis (EPPA) Model: Version 4. MIT JPSPGC Report 125, August, 72 p. (http://globalchange.mit.edu/files/document/MITJPSPGC_Rpt125.pdf).

Ramberg, D.J., 2015: General Equilibrium Impacts of New Energy Technologies on Sectoral Energy Usage: PhD Thesis, Engineering Systems Division, MIT. (http://globalchange.mit.edu/files/document/Ramberg_PhD_2015.pdf)

Riahi, K., A. Gruebler, and N. Nakicenovic, 2007: Scenarios of long-term socio-economic and environmental development under climate stabilization. Technological Forecasting and Social Change 74(7), 887-935.

Reilly, J.M., S. Paltsev, K. Strzepek, N.E. Selin, Y. Cai, K.-M. Nam, E. Monier, S. Dutkiewicz, J. Scott, M. Webster and A. Sokolov, 2013: Valuing climate impacts in integrated assessment models: the MIT IGSM. Climatic Change 117(3): 61-573.

Reimer, J. and T. W. Hertel, 2004: Estimation of International Demand Behavior for Use with Input-Output Based Data. Economic Systems Research 16(4): 347-366.

Rutherford, T.F., 1995: Extension of GAMS for Complementarity Problems Arising in Applied Economic Analysis. Journal of Economic Dynamics and Control 19: 1299-1324.

Rutherford, T.F., 1999: Applied General Equilibrium Modeling with MPSGE as a GAMS Subsystem: An Overview of the Modeling Framework and Syntax. Computational Economics 14: 1-46.

Rutherford, T.F., E.E. Rutstrom, and D.G. Tarr, 1997: Morocco's Free Trade Agreement with the European Community. Economic Modelling 14(2): 237-269.

Sato, R., 1975: The Most General Class of CES Functions. Econometrica 43(5/6): 999-1003.

Sokolov, A.P., P.H. Stone, C.E. Forest, R.G. Prinn, M.C. Sarofim, M. Webster, S. Paltsev, C.A. Schlosser, D. Kicklighter, S. Dutkiewicz, J. Reilly, C. Wang, B. Felzer, J. Melillo, H.D. Jacoby, 2009. Probabilistic Forecast for 21st Century Climate Based on Uncertainties in Emissions (without Policy) and Climate Parameters, Journal of Climate 22(19): 5175-5204. doi: 10.1175/2009JCLI2863.1.)United Nations, 2013: World Population Prospects: The 2012 Revision. Population Division, United Nations, New York, USA (http://esa.un.org/unpd/wpp/Excel-Data/population.htm).

Tapia-Ahumada, K., C. Octaviano, S. Rausch, and I. érez-Arriaga, 2015: Modeling intermittent renewable electricity technologies in general equilibrium models, Economic Modelling 51: $242-262$. 
[USDA] United States Department of Agriculture, 2013: International Food Consumption Patterns. Washington, D.C. (http://www.ers.usda.gov/data-products/international-foodconsumption-patterns.aspx\#26207).

van der Mensbrugghe, 2010: The Environmental Impact and Sustainability Applied General Equilibrium (ENVISAGE) Model. The World Bank.

(http://siteresources.worldbank.org/INTPROSPECTS/Resources/3349341314986341738/Env7_1Jan10b.pdf)

Webster, M., C. Forest, J. Reilly, M. Babiker, D. Kicklighter, M. Mayer, R. Prinn, M. Sarofim, A. Sokolov, P. Stone, and C. Wang, 2003: Uncertainty Analysis of Climate Change and Policy Response. Climate Change 61: 295-320.Webster, M., M. Babiker, M. Mayer, J.M. Reilly, J. Harnisch, R. Hyman, M.C. Sarofim, C. Wang, 2002: Uncertainty in emissions projections for climate models. Atmospheric Environment 36: 3659-3670.

Webster, M., S. Paltsev, and J. Reilly, 2008a. Autonomous efficiency improvement or income elasticity of energy demand: does it matter? Energy Economics, 30: 2785-2798, 2008.

Webster, M., S. Paltsev, J. Parsons, J. Reilly and H. Jacoby, 2008b: Uncertainty in Greenhouse Emissions and Costs of Atmospheric Stabilization, MIT Joint Program Report No. 165, (8Nov) (81 pages) (2008) http://globalchange.mit.edu/files/document/MITJPSPGC_Rpt165.pdf

Webster, M., A.P. Sokolov, J.M. Reilly, C.E. Forest, S. Paltsev, A. Schlosser, C. Wang, D. Kicklighter, M. Sarofim, J. Melillo, R.G. Prinn and H.D. Jacoby, 2012: Analysis of climate policy targets under uncertainty, Climatic Change 112(3-4) 569-583.

Winchester, N., D. McConnachie, C. Wollersheim and I.A. Waitz, 2013: Economic and emissions impacts of renewable fuel goals for aviation in the US. Transportation Research Part A: Policy and Practice 58: 116-128.

Winchester, N., and J. Reilly, 2015: The Contribution of Biomass to Emissions Mitigation under a Global Climate Policy. MIT JPSPGC Report 273, January, 31 p. (http://globalchange.mit.edu/files/document/MITJPSPGC_Rpt273.pdf)

The World Bank, 2013: China 2030: Building a Modern, Harmonious, and Creative Society. Washington, D.C. (http://documents.worldbank.org/curated/en/2013/03/17494829/china2030-building-modern-harmonious-creative-society).

The World Bank, 2015a: Official exchange rate (LCU per US\$, period average), Data. Washington, D.C. (http://data.worldbank.org/indicator/PA.NUS.FCRF?page=3).

The World Bank, 2015b: GDP Growth (annual \%), Data. Washington, D.C. (http://data.worldbank.org/indicator/NY.GDP.MKTP.KD.ZG).

World Nuclear Association, 2015: Country Profiles. London, U.K. (http://www.worldnuclear.org/info/Country-Profiles/)

Zhou, J. and M. C. Latorre, 2014: How FDI influences the triangular trade pattern among China, East Asia and the U.S.? A CGE analysis of the sector of Electronics in China, Economic Modelling 44 Supplement 1: S77-S88.

Zhou, Z., W. Tian, J. Wang, H. Liu, and L. Cao, 2012: Food Consumption Trends in China. Report submitted to the Australian Government Department of Agriculture, Fisheries and Forestry (http://www.daff.gov.au/_data/assets/pdf_file/0006/2259123/food-consumptiontrends-in-china-v2.pdf). 